\title{
Properties of Photosystem II lacking the PsbJ subunit.
}

\author{
Alain Boussac ${ }^{1}$, Julien Sellés ${ }^{2}$, Marion Hamon ${ }^{3}$, Miwa Sugiura ${ }^{4}$ \\ ${ }^{1}$ I$^{2}$ BC, UMR CNRS 9198, CEA Saclay, 91191 Gif-sur-Yvette, France. \\ ${ }^{2}$ Institut de Biologie Physico-Chimique, UMR CNRS 7141 and Sorbonne Université, 13 rue \\ Pierre et Marie Curie, 75005 Paris, France. \\ ${ }^{3}$ Institut de Biologie Physico-Chimique, UMR8226/FRC550 CNRS and Sorbonne-Université, \\ 13 rue Pierre et Marie Curie, 75005 Paris, France. \\ ${ }^{4}$ Proteo-Science Research Center, and Department of Chemistry, Graduate School of Science \\ and Technology, Ehime University, Bunkyo-cho, Matsuyama, Ehime 790-8577, Japan.
}

*Corresponding authors: alain.boussac@cea.fr, miwa.sugiura@ehime-u.ac.jp

The authors declare that they have no conflict of interest.

ORCID numbers:

Alain Boussac, 0000-0002-3441-3861

Julien Sellés, 0000-0001-9262-8257

Keywords: Photosystem II, PsbJ, plastoquinone, assembly, photoinhibition.

\section{Acknowledgments}

This work has been in part supported by i) the French Infrastructure for Integrated Structural Biology (FRISBI) ANR-10-INBS-05, ii) the Labex Dynamo (ANR-11-LABX-0011-01), iii) EQUIPEX (CACSICE ANR-11-EQPX-0008), notably through funding of the Proteomic Platform of IBPC (PPI). MS was supported by the JSPS-KAKENHI grant in Scientific Research on Innovative Areas JP17H06435 and a JSPS-KAKENHI grant 21H02447. 


\section{Abbreviations:}

Chl, chlorophyll; ChlD1/ChlD2, accessory Chl's on the D1 or D2 side, respectively; DCMU, 3(3,4-dichlorophenyl)-1,1-dimethylurea; PSII, Photosystem II; MES, 2-(N-morpholino) ethanesulfonic acid; $\mathrm{P}_{680}$, primary electron donor; $\mathrm{P}_{\mathrm{D} 1}$ and $\mathrm{P}_{\mathrm{D} 2}$; Chl monomer of $\mathrm{P}_{680}$ on the D1 or D2 side, respectively, Phed1 and PheD2, pheophytin on the D1 or D2 side, respectively; $\mathrm{Q}_{\mathrm{A}}$, primary quinone acceptor; $\mathrm{Q}_{\mathrm{B}}$, secondary quinone acceptor; $\mathrm{Ty}_{\mathrm{D}}$, redox active tyrosine 160 of D2; Tyrz, redox active tyrosine 161 of D1; TL, thermoluminescence; WT*3, T. elongatus mutant strain containing only the $p s b A_{3}$ gene and a His6-tag on the C-terminus of CP43. EPR, Electron Paramagnetic Resonance spectroscopy; MALDI-TOF, Matrix Assisted Laser Desorption Ionization - Time of Flight. 


\begin{abstract}
Photosystem II (PSII), the oxygen-evolving enzyme, consists of 17 trans-membrane and 3 extrinsic membrane proteins. Other subunits bind to PSII during assembly, like Psb27, Psb28, Ts10063. The presence of Psb27 has been proposed (Zabret et al. 2021; Huang et al. 2021; Xiao et al. 2021) to prevent the binding of PsbJ, a single transmembrane $\alpha$-helix close to the quinone Qв binding site. Consequently, a PSII rid of Psb27, Psb28 and Ts10034 prior to the binding of PsbJ would logically correspond to an assembly intermediate. The present work describes experiments aiming at further characterizing such a $\Delta$ PsbJ-PSII, purified from the thermophilic Thermosynechococcus elongatus, by means of MALDI-TOF spectroscopy, Thermoluminescence, EPR spectroscopy and UV-visible time-resolved spectroscopy. In the purified $\triangle \mathrm{PsbJ}$-PSII, an active $\mathrm{Mn}_{4} \mathrm{CaO}_{5}$ cluster is present in $60-70 \%$ of the centers. In these centers, although the forward electron transfer seems not affected, the $E m$ of the $\mathrm{Q}_{\mathrm{B}} / \mathrm{Q}_{\mathrm{B}}{ }^{-}$ couple increases by $\geq 120 \mathrm{mV}$ thus disfavoring the electron coming back on QA. The increase of the energy gap between $\mathrm{Q}_{A} / \mathrm{Q}_{\mathrm{A}^{-}}$and $\mathrm{Q}_{\mathrm{B}} / \mathrm{Q}_{\mathrm{B}}{ }^{-}$could contribute in a protection against the charge recombination between the donor side and $\mathrm{Q}_{\mathrm{B}}^{-}$, identified at the origin of photoinhibition under low light (Keren et al. 1997), and possibly during the slow photoactivation process.
\end{abstract}




\section{Introduction}

Photosystem II (PSII), the water-splitting enzyme in cyanobacteria, algae and higher plants, is responsible for the production of the atmospheric $\mathrm{O}_{2}$ that is essential for aerobic organisms and it is the first step in the production of food, fibers and fossil fuels. The mature Photosystem II, in cyanobacteria, consists of 20 subunits (Umena et al. 2011; Suga et al. 2015) with 17 trans-membrane and 3 extrinsic membrane proteins (Roose et al. 2016). The PSII also binds 35 chlorophylls, 2 pheophytins, 2 hemes, 1 non-heme iron, 2 plastoquinones (QA and Qв), the $\mathrm{Mn}_{4} \mathrm{CaO}_{5}$ cluster, $2 \mathrm{Cl}^{-}, 12$ carotenoids and 25 lipids (Umena et al. 2011; Suga et al. 2015). Most of the cofactors involved in the water oxidation and electron transfer bind to the reaction center subunits, PsbA (also called D1) and PsbD (also called D2).

The first step in the photosynthetic electron transfer chain is the absorption of a photon by the antenna chlorophyll. Then, the excitation is transferred to the photochemical trap that includes the four chlorophylls $\mathrm{P}_{\mathrm{D} 1}, \mathrm{P}_{\mathrm{D} 2}$, ChlD1 and ChlD2. After a few picoseconds following the light-absorption process a charge separation occurs forming the $\mathrm{Chl}_{\mathrm{D} 1}{ }^{+} \mathrm{Phe}_{\mathrm{D} 1}{ }^{-}$and then the $\mathrm{PD}^{+}{ }^{+} \mathrm{PheD1}{ }^{-}$radical pairs (Holzwarth et al. 2006; Romero et al. 2017). Then, $\mathrm{P}_{\mathrm{D} 1}{ }^{+}$oxidizes Tyrz, the Tyr161 of the D1 polypeptide, which in turn oxidizes the $\mathrm{Mn}_{4} \mathrm{CaO}_{5}$ cluster, see (Shen 2015, Cox et al. 2020) for reviews. The electron on Phed1 ${ }^{-}$is then transferred to $\mathrm{Q}_{\mathrm{A}}$, the primary quinone electron acceptor and then to $\mathrm{Q}_{\mathrm{B}}$, the second quinone electron acceptor. Whereas $Q_{\text {A }}$ is only singly reduced under normal conditions, $Q_{в}$ accepts two electrons and two protons before to leave its binding site, reviewed in (de Causmaecker et al. 2019). The $\mathrm{Mn}_{4} \mathrm{CaO}_{5}$ cluster is sequentially oxidized following each charge separation so that it cycles through five redox states denoted $S_{n}$, where $n$ stands for the number of stored oxidizing equivalents (Kok et al. 1970; Joliot and Kok 1975). When the S4-state is formed, i.e. after the $3^{\text {rd }}$ flash of light given on dark-adapted PSII that is in the $\mathrm{S}_{1}$ state, the two water molecules bound to the cluster are oxidized, the $\mathrm{O}_{2}$ is released and the $\mathrm{S}_{0}$-state is reformed.

In cyanobacteria, in addition to the subunits involved in the cofactors binding (PsbA, PsbD, CP43, CP47, PsbE, PsbF), there are several small subunits consisting in only a transmembrane $\alpha$-helix as PsbT, PsbM, PsbJ, PsbK, PsbL, PsbI, PsbX, PsbY, Psb30 (formerly Ycf12), e.g.( Kashino et al. 2002, 2007; Nowaczyk et al. 2012; Sugiura et al. 2012). Some roles have been attributed to these low molecular weight subunits either upon site directed mutagenesis, mainly for PsbT, or upon the deletion of the protein as for PsbM, PsbJ, Psb30, PsbK, PsbX, PsbZ. 
It has been proposed that the interaction between Phe239 of PsbA and the PsbT subunit is required to restrict the movement of the DE loop of PsbA. In turn, the disruption of this interaction may perturb the binding of bicarbonate to the non-heme iron that could contribute to the signal for PSII to undergo a repair following photodamages (Forsman and Eaton-Rye 2021). Deletion of PsbM has been reported to mainly affect the $Q_{в}$ environment (Uto et al. 2017). PSII depleted of Psb30 exhibited a lower efficiency under high light conditions and Psb30 favors the stabilization of the PSII complex (Sugiura et al. 2010a; Inoue-Kashino et al. 2011). Deletion of PsbK has been proposed to destabilize the association of PsbZ and Psb30 (Ycf12) with PSII complex and to alter the Qв function (Iwai et al. 2010). PsbZ has been proposed to stabilize the binding of Psb30 (Takasaka et al. 2010). Deletion of PsbX has been shown to affect the PSII integrity in both Arabidopsis thaliana (Garcia-Cerdan et al. 2009) and Synechocystis sp. PCC 6803 (Funk 2000). In plant PSII, the PsbL subunit seems to prevent the back electron flow from the reduced plastoquinol pool thus protecting the PSII from photoinactivation (Ohad et al. 2004). In Synechocystis sp. PCC 6803, PsbL also influences forward electron transfer from $\mathrm{Q}_{\mathrm{A}}{ }^{-}$to $\mathrm{Q}_{\mathrm{B}}$ (Luo et al. 2014).

The $p s b J$ gene belongs to the $p s b E F L J$ operon coding for the PsbE and PsbF subunits bearing the two histidine residues His23 and His24, respectively, which are the heme iron axial ligands of the Cytb559 (Umena et al. 2011). The PsbJ subunit is close to PsbK and its possible involvement in the exchange of the plastoquinone has been discussed (Kaminskaya et al. 2007; Müh et al. 2012; van Eerden et al. 2017) with a role in the efficiency of forward electron flow following the charge separation process by affecting the $\mathrm{Q}_{\mathrm{A}}$ and $\mathrm{Q}_{\mathrm{B}}$ properties (Ohad et al. 2004; Regel et al. 2001). In Synechocystis sp. PCC 6803, double mutants lacking PsbJ and either PsbV or PsbO are unable to grow photoautotrophically (Choo et al. 2021).

In most of the deletion mutants, the observed phenotype is an alteration of the acceptor side. However, it is difficult to attribute these changes more to a specific role of the deleted subunits, rather than to perturbations in the overall structure of PSII. Cyanobacteria have several PsbA isoforms (Mulo et al. 2009; Sugiura and Boussac, 2014; Sheridan et al. 2020). In Thermosynechococcus elongatus, the deletion of the $p s b J$ gene has different consequences with either PsbA1 or PsbA3 as the D1 protein. In PsbA3-PSII, the effects are minor whereas in the purified $\triangle \mathrm{PsbJ}$-PsbA1/PSII several other subunits including PsbY, PsbU, and PsbV are lacking (Sugiura et al. 2010b). In contrast, Psb27, Psb28 and Ts10063, have been found to be associated to a proportion of the $\Delta$ PsbJ-PsbA1/PSII (Nowaczyk et al. 2012). These three proteins are known to be PSII assembly factors (Nowaczyk et al. 2006; Roose and Pakrasi 2008; Komenda et al. 2012; Liu et al. 2013; Huang et al. 2021; Zabret et al. 2021). It should 
be noted that Ts10063 is named either Psb34 in (Zabret et al. 2021) or Psb36 in (Xiao et al. 2021). Structures of PSII corresponding to assembly intermediates have been recently solved by using cryo-EM by using different strategies (Zabret et al. 2021; Huang et al. 2021; Xiao et al. 2021). Upon deletion of the $p s b J$ gene it became possible to isolate a "PSII-I" intermediate with Psb27, Psb28 and Ts10063 bound and in which the major conformational change was a distortion of the $\mathrm{Q}_{в}$ binding site and the replacement of bicarbonate with glutamate as a ligand of the non-heme iron (Zabret et al. 2021). From a $p s b V$ deletion mutant a dimeric Psb27-PSII (Huang et al. 2021) and Psb28-PSII (Xiao et al. 201) have also been purified in which the dissociation of PsbJ occurs. Such changes are proposed to protect the PSII from damage during biogenesis until an active $\mathrm{Mn}_{4} \mathrm{CaO}_{5}$ cluster is assembled (Zabret et al. 2021; Xial et al. 2021).

Since the presence of Psb27 prevents the binding of PsbU and induces the dissociation of PsbJ and PsbY (Huang et al. 2021) and since PsbJ also seems to trigger the release of Psb28 (Zabret et al. 2021), the binding of PsbJ during the PSII assembly process very likely occurs after the release of Psb27 and Psb28. Consequently, a PSII without Psb27, Psb28, Ts10063, and without PsbJ would logically also correspond to an assembly intermediate. In the present work, we describe the results of experiments aiming at further characterizing the $\Delta$ PsbJ-PsbA1/PSII purified from Thermosynechococcus elongatus by means of MALDI-TOF spectroscopy, Thermoluminescence, EPR spectroscopy and UV-visible time-resolved spectroscopy.

\section{Materials and Methods}

\section{Samples used}

The Thermosynechococcus elongatus strains used were; i) the $\Delta p s b A_{2}, \Delta p s b A_{3}$ deletion mutant, referred to as either WT*1-PSII or PsbA1-PSII, ii) the $\Delta p s b A_{1}, \Delta p s b A_{2}$ deletion mutant, referred to as either WT*3-PSII or PsbA3-PSII (Sugiura et al. 2010b), and iii) the $\Delta$ PsbJ-43H deletion mutant (Sugiura et al. 2010b) which has the three $p s b A$ genes but in which only the PsbA1-PSII is produced under the culture conditions used in this work, see thereafter. These strains were constructed from the T. elongatus 43-H strain that had a His6tag on the carboxy terminus of CP43 (Sugiura and Inoue 1999). PSII purification was achieved as previously described (Sugiura et al. 2014). The final resuspending medium 
contained $1 \mathrm{M}$ betaine, $15 \mathrm{mM} \mathrm{CaCl} 2,15 \mathrm{mM} \mathrm{MgCl}_{2}, 40 \mathrm{mM}$ Mes, pH 6.5 adjusted with $\mathrm{NaOH}$.

\section{MALDI-TOF measurements}

All reagents and solvents were purchased from Sigma-Aldrich (Saint QuentinFallavier, France) with the highest purity available. Peptides and protein used for calibration were purchased from LaserBio Labs (TOF Mix) and Sigma (equine apomyoglobin), respectively. For intact mass analysis, $1 \mu \mathrm{L}$ of PSII complex prepared at a concentration of $\sim 100 \mu \mathrm{g} \mathrm{Chl} / \mathrm{mL}$ in the medium mentioned above was mixed with $2 \mu \mathrm{L}$ of a saturated solution of sinapinic acid in 60/0.1 acetonitrile/trifluoroacetic acid. Two microliters of this premix were spotted onto the sample plate and allowed to dry under a gentle air stream. Spectra were acquired in positive reflectron and linear mode on an Axima Performance MALDI-TOF/TOF mass spectrometer (Shimadzu, Manchester, UK) with a pulse extraction fixed at 4000 for $3000-10000 \mathrm{~m} / \mathrm{z}$ range and at 10000 for $6000-20000 \mathrm{~m} / \mathrm{z}$ range acquisitions. All spectra were externally calibrated using a homemade calibrant mixture prepared by mixing $1 \mu \mathrm{L}$ of $50 \mu \mathrm{M}$ apomyoglobine in water with $2 \mu \mathrm{L}$ of TOF Mix solution containing $\mathrm{ACTH}[7-38]$ peptide at a concentration of $6 \mu \mathrm{M}$.

\section{UV-visible time-resolved absorption change spectroscopy}

Absorption changes measurements have been performed with a lab-built spectrophotometer (Béal et al. 1999) in which the absorption changes were sampled at discrete times by short analytical flashes. These analytical flashes were provided by an optical parametric oscillator (Horizon OPO, Amplitude Technologies) pumped by a frequency tripled Nd:YAG laser (Surelite II, Amplitude Technologies), producing monochromatic flashes (355 nm, $2 \mathrm{~nm}$ full-width at half-maximum) with a duration of $5 \mathrm{~ns}$. Actinic flashes were provided by a second Nd:YAG laser (Surelite II, Amplitude Technologies) at $532 \mathrm{~nm}$, which pumped an optical parametric oscillator (Surelite OPO plus) producing monochromatic saturating flashes at $695 \mathrm{~nm}$ with the same pulse-length. The two lasers were working at a frequency of $10 \mathrm{~Hz}$. The time delay between the laser delivering the actinic flashes and the laser delivering the detector flashes was controlled by a digital delay/pulse generator (DG645, jitter of 1 ps, Stanford Research). The path-length of the cuvette was $2.5 \mathrm{~mm}$.

The samples were diluted in $1 \mathrm{M}$ betaine, $15 \mathrm{mM} \mathrm{CaCl}_{2}, 15 \mathrm{mM} \mathrm{MgCl}_{2}$, and $40 \mathrm{mM}$ Mes (pH 6.5). PSII samples were dark-adapted for $\sim 1 \mathrm{~h}$ at room temperature $\left(20-22^{\circ} \mathrm{C}\right)$ before, when indicated, the addition of $0.1 \mathrm{mM}$ phenyl $p$-benzoquinone (PPBQ) dissolved in 
dimethyl sulfoxide. The chlorophyll concentration of all the samples was $\sim 25 \mu \mathrm{g}$ of $\mathrm{Chl} / \mathrm{mL}$. After the $\Delta \mathrm{I} / \mathrm{I}$ measurements, the absorption of each diluted batch of samples was precisely controlled to avoid errors due to the dilution of concentrated samples and the $\Delta \mathrm{I} / \mathrm{I}$ values were normalized to $A_{673}=1.75$, with $\varepsilon \sim 70 \mathrm{mM}^{-1} \cdot \mathrm{cm}^{-1}$ at $674 \mathrm{~nm}$ for dimeric PSII (Müh and Zouni 2005).

\section{EPR spectroscopy}

X-band cw-EPR spectra were recorded with a Bruker Elexsys 500 spectrometer equipped with a standard ER 4102 (Bruker) X-band resonator, a Bruker teslameter, an Oxford Instruments cryostat (ESR 900) and an Oxford ITC504 temperature controller. Flash illumination at room temperature was provided by a neodymium:yttrium-aluminum garnet (Nd:YAG) laser (532 nm, $550 \mathrm{~mJ}, 8 \mathrm{~ns}$ Spectra Physics GCR-230-10). Illumination at $198 \mathrm{~K}$ with visible light was done in a non-silvered Dewar filled with ethanol cooled with dry ice for approximately 5-10 seconds with a $800 \mathrm{~W}$ tungsten lamp filtered by water and infrared cut-off filters. Illumination at $4.2 \mathrm{~K}$ was done in the EPR cavity using a low-voltage halogen lamp (24V, 250W, Philips Type 13163) filtered by water and infrared cut-off filters. After a $1 \mathrm{~h}$ dark-adaptation at room temperature the samples were frozen in the dark to $198 \mathrm{~K}$ in a dry ice ethanol bath and then transferred to $77 \mathrm{~K}$ in liquid $\mathrm{N}_{2}$. Prior to the recording of the spectra the samples were degassed at $198 \mathrm{~K}$.

\section{Thermoluminescence measurements}

Thermoluminescence (TL) curves were measured with a lab-built apparatus (Ducruet 2003; Ducruet and Vass 2009). PSII samples were diluted in $1 \mathrm{M}$ betaine, $40 \mathrm{mM}$ MES, 15 $\mathrm{mM} \mathrm{MgCl} 2,15 \mathrm{mM} \mathrm{CaCl}_{2}, \mathrm{pH} 6.5$ and then dark-adapted for at least $1 \mathrm{~h}$ at room temperature. When used, DCMU (100 $\mu \mathrm{M}$, final concentration), dissolved in ethanol, was added after the dark-adaptation. Flash illumination was given at $-10^{\circ} \mathrm{C}$ by using a saturating xenon flash. Two reasons justifies the choice of this temperature. Firstly, with the resuspending medium used, the freezing/melting of the samples occurs at $\sim-15^{\circ} \mathrm{C}$. Since the frozen samples are strongly diffusing, the flash illumination was done at a temperature slightly above $-15^{\circ} \mathrm{C}$. Secondly, an artefact occurs in the melting region which makes difficult the detection of small signals. It has been checked after the dilutions that the PSII samples had the same OD at $673 \mathrm{~nm}$ equal to 0.70 i.e. $\sim 10 \mu \mathrm{g} \mathrm{Chl/mL.}$ 
The measurements have been done on two different $\Delta$ PsbJ-PSII preparations with at least two measurements on each PSII samples except for the period 4 oscillation experiment at $291 \mathrm{~nm}$ done on only one PSII preparation. In addition to MALDI-TOF analysis, the protein content of the $\triangle$ PsbJ-PSII has been previously monitored with SDS-page and the oligomeric state of PSII was also analyzed by gel permeation (Sugiura et al. 2010b). Most of the $\triangle \mathrm{PsbJ}$-PSII, although not all, was in monomeric form and there was no evidence for the presence of any of the 3 proteins Psb28, Psb27 and Ts10063 in significant amounts. For the spectroscopic measurements all samples were dark-adapted for one hour at room temperature before the measurements for allowing a full decay of $S_{2}$ and $S_{3}$ into $S_{1}$ (Sugiura et al. 2004).

\section{Results}

Before to study the effects of the PsbJ deletion some control experiments were performed. Indeed, it has been reported (Nowaczyk et al. 2012) that in T. elongatus cells having all the $p s b A 1, p s b A 2$ and $p s b A 3$ genes, and the $p s b J$ gene inactivated by insertion of a cassette, PsbA1 was replaced by PsbA3 in the $\triangle$ PsbJ-PSII. Although this substitution was not observed in the most recent work done by the same group (Zabret et al. 2021) it seemed important to us to verify that the D1 subunit was indeed PsbA1 in our $\triangle \mathrm{PsbJ}-43 \mathrm{H} / \mathrm{PSII}$ which also contains the 3 genes, $p s b A 1, p s b A 2$ and $p s b A 3$. For that, we have recorded the electrochromic blue shift undergone by PheD1 in the Qx spectral region upon the formation of $\mathrm{QA}^{-}$. This electrochromic C-550 band shift is well known to be red shifted by $\sim 3.0 \mathrm{~nm}$ from $544 \mathrm{~nm}$ in PsbA1-PSII to $547 \mathrm{~nm}$ in PsbA3-PSII. This shift reflects a hydrogen bond from the $13^{1}$-keto $\mathrm{C}=\mathrm{O}$ group of Phe 1 stronger with the carboxylate group of E130 in PsbA3-PSII than with the amine group of Q130 in PsbA1-PSII (Merry et al. 1998; Cuni et al. 2004; Hughes et al. 2010; Shibuya et al. 2010).

Figure 1 shows the C-550 bandshift with PsbA1-PSII (black spectrum), in PsbA3-PSII (blue spectrum) and in $\triangle \mathrm{PsbJ}-43 \mathrm{H} / \mathrm{PSII}$ (red spectrum). For these measurements, the samples were first dark-adapted for one hour at room temperature. Then, the absorption changes were measured $15 \mu$ s after each actinic flash in a series in the presence of PPBQ. The data points are the average of the individual absorption changes induced by the $2^{\text {nd }}$ to $7^{\text {th }}$ flashes. In the $\Delta \mathrm{PsbJ}-43 \mathrm{H} / \mathrm{PSII}$ the electrochromic band shift was similar to that in the PsbA1/PSII sample, showing unambiguously that the D1 protein is PsbA1 in the $\Delta \mathrm{PsbJ}-43 \mathrm{H} / \mathrm{PSII}$. 
Secondly, the polypeptide content was analysed in WT*1-PSII and $\Delta$ PsbJ-43H/PSII with MALDI-TOF spectroscopy. Panel A in Figure 2 shows the $\mathrm{m} / \mathrm{z}$ region from 3500 to 6500. The inset in Panel A shows the $\mathrm{m} / \mathrm{z}$ region corresponding to PsbM (4009 Da calc.) and PsbJ (4002 Da calc.) by a using the reflection mode. The different peaks for one protein correspond to the different proportions of ${ }^{13} \mathrm{C}$ in the proteins starting from no ${ }^{13} \mathrm{C}\left(100 \%{ }^{12} \mathrm{C}\right)$ to $1,2,3$, and so on, ${ }^{13} \mathrm{C}$ per protein. The two peaks for PsbJ spaced by $\sim 16 \mathrm{~m} / \mathrm{z}$ likely correspond to an oxygen adduct for the larger $\mathrm{m} / \mathrm{z}$ value, also seen in earlier reports as in (Sugiura et al. 2010b;Nowaczyk et al. 2012). Panel B in Figure 2 shows the $m / z$ region from 6500 to 16000 . The PsbJ subunit, as expected, is missing in the $\Delta$ PsbJ-43H/PSII (Sugiura et al. 2010b; Nowaczyk et al. 2012). In $\Delta$ PsbJ-43H/PSII, other subunits are missing as PsbY, PsbU, PsbV (the Cytc550) as previously observed. However, PsbM and PsbF are now detected in $43 \mathrm{H} / \Delta \mathrm{PsbJ}$-PSII exhibiting a peak with an amplitude comparable to that in WT*1-PSII and with a single peak for PsbM while two peaks (native and formylated) were previously observed in (Sugiura et al. 2010b). The reasons for such a difference between the two observations is at present unclear. A reexamination of the raw data in (Sugiura et al. 2010b) indicates that at that time we did not pay attention to the possible presence of Psb28 in a very small proportion of our $\Delta$ PsbJ-43H/PSII. Indeed, a very small peak at $m / z \sim 12787$ was present (Sugiura et al. 2010b). Panel B in Figure 2 also shows a very small peak at 12787 that could well correspond to Psb28. However, the amplitude of this peak is close to the limit of the detection. A small peak detected at $m / z=13424$ in some traces could correspond to Psb27 (not shown). A peak at $m / z=5936$, not attributed in (Sugiura et al. 2010b) could originate from Ts10063 recently detected in $\triangle$ PsbJ-PsbA1/PSII (Zabret et al. 2021). This protein is however not detected in Figure 2. The MALDI-TOF data described above in comparison with those in literature show that upon the deletion of PsbJ in PsbA1-PSII, the PSII composition may slightly vary from prep to prep. If present, the 3 proteins Psb27, Psb28 and Ts10063 are in a so minor proportion of the $\Delta \mathrm{PsbJ}-43 \mathrm{H} / \mathrm{PSII}$ studied here that this proportion will not contribute significantly to the results described thereafter. We cannot eliminate the possibility that these 3 proteins are removed during the PSII purification. This, however, does not modify the fact that the studied $\Delta$ PsbJ-43H/PSII does not bind Psb27, Psb28 and Ts10063.

In Synechocystis 6803, the deletion of PsbJ has been proposed to alter both the forward electron flow from $\mathrm{QA}^{-}$to the plastoquinone pool and the back reaction between $\mathrm{QA}^{-}$ and the oxidized $\mathrm{Mn}_{4} \mathrm{CaO}_{5}$ cluster (Regel et al. 2001). These conclusions were done in part from thermoluminescence experiments (Rutherford et al. 1982) in whole cells. Here, similar 
measurements have been done but in purified WT*1-PSII and $\Delta \mathrm{PsbJ}-43 \mathrm{H} / \mathrm{PSII}$. Figure 3 shows the TL curves after 1 flash given at $-10^{\circ} \mathrm{C}$ in WT*1-PSII, black traces, and $\Delta$ PsbJ43H/PSII, red traces. In Panel A, the TL measurements were done without any addition whereas in Panel B they were done in the presence of DCMU. The TL curves in WT*1-PSII arising from the $\mathrm{S}_{2} \mathrm{Q}_{\mathrm{B}}{ }^{-}$charge recombination in Panel $\mathrm{A}$ with a peak temperature at $\sim 43^{\circ} \mathrm{C}$ and from the $\mathrm{S}_{2} \mathrm{Q}_{\mathrm{A}}{ }^{-} / \mathrm{DCMU}$ charge recombination in Panel $\mathrm{B}$ with a peak temperature at $\sim 13^{\circ} \mathrm{C}$ are those expected in T. elongatus with an heating rate of $0.4^{\circ} \mathrm{C} / \mathrm{s}$. In $\Delta \mathrm{PsbJ}-43 \mathrm{H} / \mathrm{PSII}$, no signal was detected both in Panels A and B. The very small signal around $0^{\circ} \mathrm{C}$ in Panels $\mathrm{A}$ and B is very similar in the absence and the presence of DCMU and therefore cannot arise from the $\mathrm{S}_{2} \mathrm{Q}_{\mathrm{B}}{ }^{-}$and $\mathrm{S}_{2} \mathrm{Q}_{\mathrm{A}}{ }^{-} / \mathrm{DCMU}$ charges recombinations studied here. The TL results in Figure 3 differ significantly from those in Synechocystis whole cells where in the $\Delta \mathrm{PsbJ}$ mutant a small TL signal was detected at a slightly lower temperature for the $\mathrm{S}_{2} \mathrm{Q}_{\mathrm{B}}{ }^{-}$charge recombination and at a slightly higher temperature for the $\mathrm{S}_{2} \mathrm{Q}_{\mathrm{A}}{ }^{-} / \mathrm{DCMU}$ charge recombination (Regel et al. 2001). However, the amplitude of a TL signal depends on the proportion of centers with $\mathrm{Q}_{\mathrm{B}}{ }^{-}$in the dark-adapted state, something that is difficult to control in whole cells. The lack of a TL signal in $\triangle \mathrm{PsbJ}-43 \mathrm{H} / \mathrm{PSII}$ both with and without DCMU may be explained if $100 \%$ of the centers are in the $\mathrm{Q}_{\mathrm{B}}{ }^{-}$state upon the dark adaptation. As this will be shown later, that is not the case in the $\Delta \mathrm{PsbJ}-43 \mathrm{H} / \mathrm{PSII}$ studied here and we have to find another explanation.

The first simple explanation is that the radiative charge recombination in the $\Delta \mathrm{PsbJ}-$ 43H/PSII occurs either $i$ ) at a temperature much above a bearable temperature for PSII (i.e. $>60^{\circ} \mathrm{C}$ ) or ii) at a temperature much lower than $0^{\circ} \mathrm{C}$. In the first case, the $E m$ of the $\mathrm{QA}_{\mathrm{A}} / \mathrm{QA}^{-}$ couple, upon the deletion of PsbJ, would be strongly increased and, in the second case, strongly decreased. The second possibility could be a situation in which the $\mathrm{Mn}_{4} \mathrm{CaO}_{5}$ cluster in the $\Delta \mathrm{PsbJ}-43 \mathrm{H} / \mathrm{PSII}$ is inactive or lost because we know that under continuous illumination the activity is significantly decreased (Sugiura et al. 2010b).

Before to go further in the interpretation of the TL experiments we have therefore performed some EPR measurements for clarifying the situation.

Figure 4 shows the EPR spectra recorded at $8.6 \mathrm{~K}$ in dark-adapted samples (black spectra) and after a continuous illumination at $198 \mathrm{~K}$ (red spectra). The blue spectra are the light-minus-dark spectra. At $198 \mathrm{~K}$, the electron transfers from $\mathrm{Q}_{\mathrm{A}^{-}}$to $\mathrm{Q}_{\mathrm{B}}$ and from $\mathrm{Q}_{\mathrm{A}^{-}}$to $\mathrm{Q}_{\mathrm{B}}{ }^{-}$ are blocked so that only one charge separation may occur (Fufezan et al. 2005). In WT*1PSII, the black spectrum is very similar to the spectrum recorded in PsbA3-PSII under the 
same conditions, see (Boussac et al. 2011) for a detailed description of the spectra. The signal between 3600 and 5000 gauss originates from $\mathrm{Fe}^{2+} \mathrm{QB}^{-}$(Fufezan et al. 2005; Boussac et al. 2011; Sedoud et al. 2011). After illumination at $198 \mathrm{~K}$ for $\sim 5-10 \mathrm{~s}$, the $\mathrm{S}_{2}$ multiline signal was formed together with a signal at $g=1.6(\sim 4100$ gauss $)$. The $g=1.6$ signal originates from the $\mathrm{Q}^{-}{ }^{-} \mathrm{Fe}^{2+} \mathrm{Q}_{\mathrm{B}}{ }^{-}$state. The $\mathrm{Q}_{\mathrm{A}}{ }^{-} \mathrm{Fe}^{2+}$ signal formed in centers with $\mathrm{Q}_{\mathrm{B}}$ oxidized prior to the illumination is difficult to detect in the presence of the multiline signal. A careful examination of the blue spectrum in the $g=6$ to $g=8$ region indicates that the non-heme iron was oxidized in a very small fraction of the dark-adapted centers and was reduced upon the $198 \mathrm{~K}$ illumination (Boussac et al. 2011). The spectrum in the dark-adapted $\Delta \mathrm{PsbJ}-43 \mathrm{H} / \mathrm{PSII}$ also exhibits a $\mathrm{Fe}^{2+} \mathrm{QB}^{-}$signal with a somewhat smaller amplitude (see also Figure 7) than in WT*1-PSII. This observation rules out the hypothesis that the lack of a TL signal is due to centers with $100 \% \mathrm{Q}^{-}$in the dark-adapted state. In agreement with the MALDI-TOF data above, and as previously reported (Sugiura et al. 2010b), the EPR also shows that the Cytc550 (PsbV) is missing in the purified PSII as evidenced by the much smaller signals at $g \sim 3$ and $g$ $\sim 2.2$ (3000 gauss) corresponding to the $g_{\mathrm{z}}$ and $g_{\mathrm{y}}$ resonances of cytochrome signals, respectively (the $g_{\mathrm{x}}$ feature is difficult to detect under the conditions used for the recording of these spectra). We have nevertheless previously shown that PsbV was detectable in the $\Delta$ PsbJ-43H/thylakoids (Sugiura et al. 2010b). Cytb559 is detected because it is in the low potential oxidized form in $\Delta$ PsbJ-43H/PSII (Sugiura et al. 2010). The detection of a signal at $g$ $=6(\sim 1100$ gauss $)$ indicates that a proportion of Cytb559 is also present in an oxidized high $\operatorname{spin}(S=5 / 2)$ configuration. Importantly, the $S_{2}$ multiline signal is detectable upon the $198 \mathrm{~K}$ illumination with an amplitude close to $60-70 \%$ of that in WT*1-PSII. Therefore, the total absence of a TL signal in this sample is also not due to an inactive or missing $\mathrm{Mn}_{4} \mathrm{CaO}_{5}$ cluster. The proportion of $\Delta \mathrm{PsbJ}-43 \mathrm{H} / \mathrm{PSII}$ in which the $\mathrm{Mn}_{4} \mathrm{CaO}_{5}$ is able to progress to the $\mathrm{S}_{2}$ state upon an illumination at $198 \mathrm{~K}$ is higher than the $\mathrm{O}_{2}$ evolution activity found in this PSII that is about $30 \%$ (Sugiura et al. 2010b). However, it is well known that the $\mathrm{O}_{2}$ activity under continuous illumination does not necessarily correlate with the proportion of active centers. For example, upon the substitution of $\mathrm{Ca}^{2+}$ for $\mathrm{Sr}^{2+}$ the $\mathrm{O}_{2}$ activity under continuous illumination is decreased by a least of factor of 2 whereas all the centers are fully active (Ishida et al. 2008). In an additional control experiment (not shown) aiming at following the period four oscillation measured at $291 \mathrm{~nm}$ and $100 \mathrm{~ms}$ after each flash of a series (Lavergne 1991; Ishida et al. 2008) it has been found that in the $\Delta \mathrm{PsbJ}-43 \mathrm{H} / \mathrm{PSII}$ the miss parameter is close to $20 \%$ instead of $\sim 8 \%$ in the PsbA1-PSII. 
The remaining possible explanations for the lack of a TL signal in $\triangle \mathrm{PsbJ}-43 \mathrm{H} / \mathrm{PSII}$ are either $i$ ) an inefficient charge separation after one flash illumination in contrast to the continuous illumination at $198 \mathrm{~K}$, and/or ii) a too fast, even at $-10^{\circ} \mathrm{C}$, or too slow charge recombination in the temperature range probed by the TL thus preventing the detection of the signal. These possibilities have been tested in the EPR experiments reported in Figure 5 and Figure 6.

Panel A in Figure 5 shows the magnetic field range in which most of the EPR signals are detectable except TyrD ${ }^{\bullet}$. The TyrD ${ }^{\bullet}$ signal is shown in Panel B. The black spectra were recorded in dark-adapted PSII and they are, of course, similar to those described in Figure 4. The green spectra have been recorded after one saturating flash given at room temperature $\left(\sim 20-22{ }^{\circ} \mathrm{C}\right)$ followed by an as-fast-as possible freezing of the sample $(\sim 2 \mathrm{~s})$ in a dry ice bath at $198 \mathrm{~K}$. Then, the red spectra were recorded after a further continuous illumination at $198 \mathrm{~K}$ following the one flash illumination. In WT*1-PSII, the difference in the amplitude of the $\mathrm{S}_{2}$ multiline between the green and red spectra is mainly due to the proportion of centers in which the $\mathrm{S}_{0} \operatorname{Tyr}_{\mathrm{D}}{ }^{\bullet}$ to $\mathrm{S}_{1} \operatorname{Tyr}_{\mathrm{D}}{ }^{\bullet}$ transition occurs with the one flash illumination. As the $\operatorname{Tyr}^{\bullet}$ signal (Panel B) does not vary significantly, this suggests that the proportion of centers in which the $\mathrm{S}_{1} \mathrm{Tyr}_{\mathrm{D}}$ to $\mathrm{S}_{1} \mathrm{TyrD}^{\bullet}$ transition occurs is negligible (Styring and Rutherford 1987).

In contrast, in $\triangle \mathrm{PsbJ}-43 \mathrm{H} / \mathrm{PSII}$, upon the illumination at $198 \mathrm{~K}$, the increase of the $\mathrm{S}_{2}$ multiline and $\operatorname{Tyr}^{\bullet}$ signals was much more pronounced than in WT*1-PSII. This results shows that in dark-adapted $\triangle \mathrm{PsbJ}-43 \mathrm{H} / \mathrm{PSII}$ there is a proportion of centers in the $\mathrm{S}_{1} \mathrm{Tyr}_{\mathrm{D}}$ state and a larger proportion of centers in the $\mathrm{S}_{0} \operatorname{Tyr}^{\bullet}$ state than in WT*1-PSII. Since the proportion of centers in the $\mathrm{Q}_{\mathrm{A}} \mathrm{Fe}^{2+} \mathrm{Q}_{\mathrm{B}}{ }^{-}$state is smaller in the $\Delta \mathrm{PsbJ}-43 \mathrm{H} / \mathrm{PSII}$ than in $\mathrm{WT}^{*} 1-$ PSII after the dark adaptation, this ratio is inversed after the one flash illumination. Consequently, the illumination at $198 \mathrm{~K}$ is expected to induce a larger $\mathrm{Q}_{\mathrm{A}}{ }^{-} \mathrm{Fe}^{2+} \mathrm{Q}_{\mathrm{B}}{ }^{-}$in $\triangle \mathrm{PsbJ}-$ 43H/PSII than in WT*1-PSII and that is indeed what is observed here. It should be mentioned that, normally, an illumination at $198 \mathrm{~K}$ is unable to oxidize TyrD in active centers. The increase seen in Panel B therefore likely occurs in the proportion of inactive $\Delta \mathrm{PsbJ}-43 \mathrm{H} / \mathrm{PSII}$. The important result in this experiment is that the one-flash illumination is able to induce the $\mathrm{S}_{2}$ state in the $\Delta \mathrm{PsbJ}-43 \mathrm{H} / \mathrm{PSII}$ although to a slightly less extent than in WT*1-PSII due to a higher proportion of centers in the $\mathrm{S}_{1} \operatorname{Tyr}_{\mathrm{D}}$ and $\mathrm{S}_{0} \mathrm{Tyr}_{\mathrm{D}}{ }^{\bullet}$ states and also to a higher miss parameter. The stability of the $\mathrm{S}_{2}$ state has then been monitored in an experiment corresponding to the TL experiment in the presence of DCMU. 
In Figure 6, the black spectra were recorded in dark-adapted PSII without any addition and the red spectra after the addition of DCMU. Two observations can be made here. Firstly, in both WT*1-PSII and $\triangle$ PsbJ-43H/PSII, the addition of DCMU resulted in the formation of $\mathrm{Q}_{\mathrm{A}}{ }^{-} \mathrm{Fe}^{2+} / \mathrm{DCMU}$ to the detriment of $\mathrm{Fe}^{2+} \mathrm{Q}_{\mathrm{B}}{ }^{-}$(Velthuys 1981). In both samples, $\mathrm{Q}_{\mathrm{A}^{-}}$ $\mathrm{Fe}^{2+} / \mathrm{DCMU}$ exhibited either the $g=1.9$ signal or the $g=1.82$ signal (Rutherford et al. 1983 , Rutherford and Zimmermann 1984), see below for a better description of the signals in Figure 6. Secondly, in WT*1-PSII, the addition of DCMU also modified the non-heme iron signal as previously observed (Diner and Petrouleas 1987). The blue spectra were then recorded after a continuous illumination at $198 \mathrm{~K}$. The $\mathrm{S}_{2}$ multiline signal was formed in the open centers, i.e. in those with no $\mathrm{QB}^{-}$prior to the addition of DCMU. The larger $\mathrm{Q}_{\mathrm{A}}{ }^{-} \mathrm{Fe}^{2+}$ signal at $g=1.9 \mathrm{in}$ $\triangle$ PsbJ-43H/PSII than in WT*1-PSII have two possible explanations: i) a lower amount of $\mathrm{QB}^{-}$ before the addition of DCMU and ii) a smaller proportion of oxidized non-heme iron. Indeed, the oxidation of $\mathrm{QA}^{-}$by the oxidized non-heme iron results in the disappearance of the nonheme iron signal is WT*1-PSII. Unfortunately, in $\Delta \mathrm{PsbJ}-43 \mathrm{H} / \mathrm{PSII}$, the presence of the high spin Cytb559 signal does not allow the detection of the non-heme iron signal.

After the illumination at $198 \mathrm{~K}$, the samples were immersed for 1 to 2 seconds, in total darkness, in an ethanol bath at $0^{\circ} \mathrm{C}$ and immediately refrozen in a dry ice bath at $198 \mathrm{~K}$ and the green spectra were recorded. In WT*1-PSII, the brief passage at $0^{\circ} \mathrm{C}$ induced almost no change in the amplitude of the $\mathrm{S}_{2}$ multiline signal. In contrast, in $\Delta \mathrm{PsbJ}-43 \mathrm{H} / \mathrm{PSII}$, almost all the $\mathrm{S}_{2}$ multiline signal and the $g=1.9$ quinone signal disappeared thus showing that the recombination in the $\mathrm{S}_{2} \mathrm{Q}_{\mathrm{A}}{ }^{-} / \mathrm{DCMU}$ state is very fast at $0^{\circ} \mathrm{C}$ in this sample. This very likely explains the lack of a TL signal in Figure 3B. The proportion of the $g=1.9$ signal which decayed during the warming at $0^{\circ} \mathrm{C}$ appears larger than the proportion the $g=1.82$ signal which decayed. This suggests that the recombination was more efficient with the quinone in the $g=1.9$ state than in the $g=1.82$ state (Demeter al. 1993; Rutherford, personal communication). Finally, the samples were immersed, in the dark, in an ethanol bath at $20^{\circ} \mathrm{C}$ and immediately refrozen in a dry ice bath at $198 \mathrm{~K}$ and the spectra in magenta were recorded. In WT*1-PSII, the $\mathrm{S}_{2}$ multiline now decreased significantly as expected from the peak temperature observed in this sample. In $\triangle \mathrm{PsbJ}-43 \mathrm{H} / \mathrm{PSII}$, the spectrum was not significantly different from that one after the thawing at $0^{\circ} \mathrm{C}$. The recording of the TyrD ${ }^{\bullet}$ spectra as in Panel B of Figure 5 showed again that $\operatorname{Tyr}^{\bullet}$ could be induced at $198 \mathrm{~K}$ and that a decay occurs upon the short incubation at $0^{\circ} \mathrm{C}$ (not shown). The experiments described above focused on the charge recombinations. In the following, we will address the forward electron transfer. 
Figure 7 shows the flash-induced $\Delta \mathrm{I} / \mathrm{I}$ and its decay at $320 \mathrm{~nm}$ after the $2^{\text {nd }}$ flash given on dark-adapted WT*3-PSII (blue), WT*1-PSII (black) and $\Delta$ PsbJ-43H/PSII (red). The $\mathrm{QA}^{-}-$ minus- $\mathrm{Q}_{\mathrm{A}}$ and $\mathrm{Q}_{\mathrm{B}}{ }^{-}-$minus- $\mathrm{Q}_{\mathrm{B}}$ difference spectra are similar and have their maximum amplitude at around $320 \mathrm{~nm}$ (Schatz and van Gorkom 1985). After the $1^{\text {st }}$ flash and the $3^{\text {rd }}$ flash, the $S_{1}$ to $S_{2}$ and $S_{3}$ to $S_{0}$ transitions also contribute significantly to the flash induced absorption changes at $320 \mathrm{~nm}$ (Lavergne 1991). In addition, the first flash is also complicated by the $\mathrm{QA}^{-}$to $\mathrm{Fe}^{2+}$ electron transfer (Boussac et al. 2011) with possible contribution in this spectral range of the $\mathrm{Fe}^{3+} / \mathrm{Fe}^{2+}$ couple (Sellés and Boussac, unpublished) and with the formation of the $\operatorname{Tyrz}^{\bullet}$ radical in inactive centers (with a flash spacing of $300 \mathrm{~ms}$, the dead centers contribute mainly on the first flash due to the slow decay of $\operatorname{Tyr}^{\bullet}$ ). For all these reasons, Figure 7 only shows the data after the second flash which is the easiest kinetics to analyze. In centers with $\mathrm{Q}_{\text {в }}$ oxidized in the dark-adapted sate the flash illumination forms the $\mathrm{Q}_{A}{ }^{-} \mathrm{Q}_{B}$ state and then the $\mathrm{Q}_{A} \mathrm{Q}_{B}{ }^{-}$state. In these centers, the flash-induced $\Delta \mathrm{I} / \mathrm{I}$ does not decay and it is responsible for the remaining stable $\Delta \mathrm{I} / \mathrm{I}$ at the longest times. In dark-adapted centers with $\mathrm{Q}_{B}{ }^{-}$present, the flash illumination forms the $\mathrm{Q}_{\mathrm{A}}{ }^{-} \mathrm{Q}_{\mathrm{B}}{ }^{-}$state and then the $\mathrm{Q}_{\mathrm{A}} \mathrm{Q}_{\mathrm{B}} \mathrm{H}_{2}$ state. This reaction is at the origin of the decay in Figure 7 and this kinetics is similar in the 3 samples with a $t_{1 / 2}$ of 2-3 ms. The similar apparent lag phase with a duration of $\sim 1 \mathrm{~ms}$ likely corresponds to the electron transfer between $\mathrm{Q}_{\mathrm{A}^{-}}$and either $\mathrm{Q}_{\mathrm{B}}$ or $\mathrm{Q}_{\mathrm{B}}{ }^{-}$. This experiment shows that the forward electron transfer is not affected by the deletion of PsbJ.

Finally, Figure 8 shows EPR spectra in WT*1-PSII (black spectra) and $\triangle$ PsbJ43H/PSII (red spectra) recorded with a magnetic field scale allowing a better observation of the quinone signals. Panel A shows the $\mathrm{Fe}^{2+} \mathrm{QB}^{-}$signal recorded in the dark-adapted samples. The signal is smaller in the $\Delta \mathrm{PsbJ}-43 \mathrm{H} / \mathrm{PSII}$ as mentioned previously and very slightly shifted. Panel B shows the spectra after a further illumination at $4.2 \mathrm{~K}$. In centers with $\mathrm{QB}^{-}$ present in the dark this $4.2 \mathrm{~K}$ illumination resulted in the formation of the $\mathrm{Q}_{\mathrm{A}}{ }^{-} \mathrm{Fe}^{2+} \mathrm{Q}_{\mathrm{B}}{ }^{-}$signal that is larger in the WT*1-PSII. In the $\Delta \mathrm{PsbJ}-43 \mathrm{H} / \mathrm{PSII}$, consequently to the larger proportion of centers with $\mathrm{Q}_{\text {в }}$ in the dark-adapted state, the $4.2 \mathrm{~K}$ illumination resulted in a larger proportion of $\mathrm{Q}_{\mathrm{A}}{ }^{-} \mathrm{Fe}^{2+} \mathrm{Q}_{\mathrm{B}}$ giving rise to the $g=1.9$ signal between 3500 and 3700 gauss. Panel $\mathrm{C}$ shows the spectra recorded after an illumination at $4.2 \mathrm{~K}$ of samples in which a low amount of ferricyanide has been added (less than $100 \mu \mathrm{M}$ ) upon the dark adaptation to have the

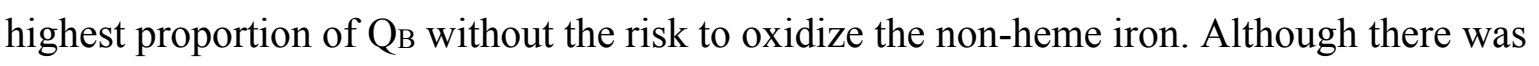
still a low amount of $\mathrm{Q}_{\mathrm{A}}{ }^{-} \mathrm{Fe}^{2+} \mathrm{Q}_{\mathrm{B}}{ }^{-}$signal in $\triangle \mathrm{PsbJ}-43 \mathrm{H} / \mathrm{PSII}$, in both samples such a procedure resulted in the formation of a similar $\mathrm{Q}_{\mathrm{A}}-\mathrm{Fe}^{2+} \mathrm{Q}_{\mathrm{B}}$ characterized by the $g=1.9$ signal. Finally, 
in Panel D the spectra were recorded after the addition of DCMU which resulted in the formation of $\mathrm{Q}_{\mathrm{A}}{ }^{-} \mathrm{Fe}^{2+} / \mathrm{DCMU}$ in centers with $\mathrm{QB}^{-}$present in the dark. Two signals are observed in the two samples, the signal at $g=1.9$ and a much broader $\sim 300$ gauss-width signal reminiscent of a signal previously observed (Sedoud et al. 2011). The larger amplitude of these two signals in WT*1-PSII resulted of the higher concentration of $\mathrm{QB}^{-}$in the dark in this PSII.

\section{Discussion}

In PSII lacking the PsbJ subunit it is possible to observe a proportion of the enzyme associated to polypeptides known to be assembly cofactors such as Psb27, Psb28 and Ts10063, and which are not detected in the mature PSII, e.g. (Nowaczyk et al. 2006; Roose and Pakrasi 2008; Komenda et al. 2012; Liu et al. 2013; Huang et al. 2021; Zabret et al. 2021). The cryo-EM structure of an intermediate state was resolved (Zabret et al. 2021) with the interesting observation that the bicarbonate ligand of non-heme iron is replaced with a glutamate (glu241 of PsbD), a structural motif found in purple bacteria. Such a motif was further proposed to protect PSII from damage during biogenesis. Although the 3 proteins Psb27, Psb28 and Ts10063 are possibility detected in the $\Delta$ PsbJ-43H/PSII studied here, the MALDI-TOF signals are so weak that we can reasonably consider that the purified PSII studied here is devoid of these assembly cofactors, see also (Sugiura et al. 2010b). The main peptides which are missing in this $\triangle \mathrm{PsbJ}-43 \mathrm{H} / \mathrm{PSII}$ are PsbY, PsbU and PsbV. Although PsbV is present in the $\Delta \mathrm{PsbJ}$-thylakoids (Sugiura et al. 2010b), the $g_{\mathrm{z}}$ value is lower than in intact PSII. This indicates (Roncel et al. 2003) that PsbV is not properly bound to PSII in thylakoids in the absence of PsbJ. Therefore, PsbJ very likely stabilizes the binding of the extrinsic peptides PsbU and PsbV and possibly of the trans-membrane $\alpha$-helix PsbY as previously suggested (Zabret et al. 2021; Huang et al. 2021; Xiao et al. 2021). The $\Delta$ PsbJ-43H/PSII is essentially monomeric (Sugiura et al. 2010b) and in agreement with such a destabilization for PsbY, it was observed that although present, no electron density corresponding to PsbY was found in a crystal of monomeric PSII (Broser et al. 2010).

Despite the close proximity of $\mathrm{PsbJ}$ with the Qв binding pocket, from the data in Figure 8, the lack of this subunit does not dramatically perturb, from an EPR point of view, any of the four states $\mathrm{Q}_{\mathrm{A}} \mathrm{Fe}^{2+} \mathrm{Q}_{\mathrm{B}}{ }^{-}, \mathrm{Q}_{\mathrm{A}}{ }^{-} \mathrm{Fe}^{2+} \mathrm{Q}_{\mathrm{B}}, \mathrm{Q}_{\mathrm{A}}{ }^{-} \mathrm{Fe}^{2+} \mathrm{QB}^{-}$and $\mathrm{Q}_{\mathrm{A}}{ }^{-} \mathrm{Fe}^{2+} / \mathrm{DCMU}$. The quinone

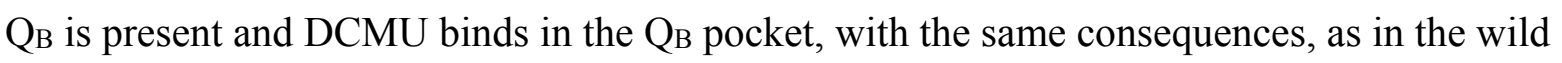


type PSII. Nevertheless, the lack of strong structural modifications, the energetics is strongly modified. Since a great proportion of $\triangle \mathrm{PsbJ}-43 \mathrm{H} / \mathrm{PSII}$ has an intact $\mathrm{Mn}_{4} \mathrm{CaO}_{5}$ cluster, this allowed us to probe these changes by using thermoluminescence (Rutherford 1982; Johnson et al. 1995; Cser and Vass 2007; Rappaport and Lavergne 2009).

In WT*1-PSII, the TL peak corresponding to the $\mathrm{S}_{2} \mathrm{Q}_{\mathrm{A}}{ }^{-} / \mathrm{DCMU}$ recombination is downshifted by $\sim 32^{\circ} \mathrm{C}$, from $45^{\circ} \mathrm{C}$ to $13^{\circ} \mathrm{C}$, when compared to the $\mathrm{S}_{2} \mathrm{Q}_{\mathrm{B}}{ }^{-}$recombination. According to a correspondence of $0.3-0.4^{\circ} \mathrm{C} / \mathrm{mV}$ estimated by Rappaport and Lavergne (2009), see also (Cser and Vass 2007), this locates the energy level of the $\mathrm{S}_{2} \mathrm{Q}_{\mathrm{A}}{ }^{-} / \mathrm{DCMU}$ state at least $80 \mathrm{mV}(=32 / 0.4)$ above the energy level of the $\mathrm{S}_{2} \mathrm{Q}_{\mathrm{B}}{ }^{-}$state in WT*1-PSII. If we assume that the $E m$ of the $\mathrm{Q}_{\mathrm{A}} / \mathrm{Q}_{\mathrm{A}}{ }^{-}$couple is increased by about $50 \mathrm{mV}$ with DCMU bound as in plant PSII (Krieger et al. 1995), this would locate the energy level of the $\mathrm{S}_{2} \mathrm{Q}_{\mathrm{A}}{ }^{-}$state at least $80+50=130 \mathrm{mV}$ above that of the $\mathrm{S}_{2} \mathrm{QB}^{-}$state in WT*1-PSII.

In $\triangle \mathrm{PsbJ}-43 \mathrm{H} / \mathrm{PSII}$ neither the $\mathrm{S}_{2} \mathrm{Q}_{\mathrm{A}}{ }^{-} / \mathrm{DCMU}$ nor the $\mathrm{S}_{2} \mathrm{Q}_{\mathrm{B}}{ }^{-}$charge recombinations are detectable in the temperature range from $-10^{\circ} \mathrm{C}$ to $70^{\circ} \mathrm{C}$. The same reasoning done above for the WT*1-PSII would locate the energy level of the $\mathrm{S}_{2} \mathrm{Q}_{\mathrm{A}}{ }^{-} / \mathrm{DCMU}$ state at least $200 \mathrm{mV}$ (= 80/0.4) above the $\mathrm{S}_{2} \mathrm{Q}_{B}{ }^{-}$state in $\triangle \mathrm{PsbJ}-43 \mathrm{H} / \mathrm{PSII}, 80^{\circ} \mathrm{C}$ being the lower limit for the difference in the TL peaks corresponding to the $\mathrm{S}_{2} \mathrm{Q}_{\mathrm{A}}{ }^{-} / \mathrm{DCMU}$ and $\mathrm{S}_{2} \mathrm{Q}_{\mathrm{B}}{ }^{-}$charge recombinations in this sample.

We cannot totally discard the possibility that the release of PsbV affects the stability of $\mathrm{S}_{2}$ in the $\Delta$ PsbJ-43H/PSII. However, Synechocystis mutants lacking PsbV exhibit TL peaks at a slightly higher temperature than in the wild type (Shen et al. 1998) suggesting an increase of the $S_{2}$ stability that is the opposite of what is seen here.

For analyzing the TL data, two extreme cases will be considered assuming that the effect of the deletion occurs mainly on the acceptor side. In the first one, the deletion of PsbJ would only affect the Em of the $\mathrm{Q}_{\mathrm{A}} / \mathrm{Q}_{\mathrm{A}}{ }^{-}$couple whereas in the second case, only the $E m$ of the $\mathrm{Q}_{\mathrm{B}} / \mathrm{Q}_{\mathrm{B}}{ }^{-}$couple would be affected. We cannot discard a possible effect on both $\mathrm{Q}_{\mathrm{A}}$ and $\mathrm{Q}_{\mathrm{B}}$. In this case, the changes will apply on $\mathrm{Q}_{\mathrm{A}}$ and $\mathrm{Q}_{\mathrm{B}}$ but to a less extent on each of them.

In the first case, we will assume that in $\triangle \mathrm{PsbJ}-43 \mathrm{H} / \mathrm{PSII}$ the binding of DCMU also increases the Em of the $\mathrm{Q}_{\mathrm{A}} / \mathrm{Q}_{\mathrm{A}}{ }^{-}$couple by $\sim 50 \mathrm{mV}$ as supposed above for WT*1/PSII. Therefore, with an energy level of the $\mathrm{S}_{2} \mathrm{Q}_{\mathrm{A}}{ }^{-} / \mathrm{DCMU}$ state at least $200 \mathrm{mV}$ above that of the $\mathrm{S}_{2} \mathrm{Q}_{B}{ }^{-}$state this would locate the energy level of the $\mathrm{S}_{2} \mathrm{Q}_{A^{-}}$state (without DCMU) at least $200+50=250 \mathrm{mV}$ above the $\mathrm{S}_{2} \mathrm{Q}_{\mathrm{B}^{-}}{ }^{-}$state in $\Delta \mathrm{PsbJ}-43 \mathrm{H} / \mathrm{PSII}$ instead of $130 \mathrm{mV}$ in WT*1-PSII. Although the value of $250 \mathrm{mV}$ could be overestimated, this high value explains the lack of the 
$\mathrm{S}_{2} \mathrm{QB}^{-}$charge recombination experimentally observed in the TL experiment and the very fast $\mathrm{S}_{2} \mathrm{Q}_{\mathrm{A}}{ }^{-} / \mathrm{DCMU}$ charge recombination. The decrease in the $E m$ of the $\mathrm{Q}_{\mathrm{A}} / \mathrm{Q}_{\mathrm{A}}{ }^{-}$couple could also explain the faster charge recombination observed in Synechocystis 6803 (Regel et al. 2001) in the absence of PsbJ if we are in conditions with a large proportion of the quinone pool fully reduced as often observed with whole cells.

In the second case, the $E m$ of the $\mathrm{Q}_{\mathrm{B}} / \mathrm{Q}_{\mathrm{B}}{ }^{-}$couple would reach a value disfavoring the electron coming back on $\mathrm{Q}_{\mathrm{A}}$. However, the energy level of the $\mathrm{S}_{2} \mathrm{Q}_{\mathrm{A}}{ }^{-} / \mathrm{DCMU}$ also need to be much higher in $\triangle \mathrm{PsbJ}-43 \mathrm{H} / \mathrm{PSII}$ than in WT*1-PSII to explain the lack of a TL signal in the presence of DCMU above $-10^{\circ} \mathrm{C}$. Since the peak in WT*1-PSII is observed at $13^{\circ} \mathrm{C}$, a peak at a temperature below $-10^{\circ} \mathrm{C}$ correspond to a decrease by at least $\sim-58 \mathrm{mV}(-23 / 0.4)$ for the $E m$ of the $\mathrm{Q}_{\mathrm{A}} / \mathrm{Q}_{\mathrm{A}}{ }^{-}$couple in the presence of DCMU when compared to WT*1-PSII. Since PsbJ is close to the Qв pocket and therefore close to the DCMU binding site, a DCMU effect on the Em of the $\mathrm{Q}_{\mathrm{A}} / \mathrm{Q}_{\mathrm{A}}{ }^{-}$couple different in $\triangle \mathrm{PsbJ}-43 \mathrm{H} / \mathrm{PSII}$ than in plant PSII would not be unlikely. If we further push the reasoning assuming no change in the Em $\mathrm{Q}_{\mathrm{A}} / \mathrm{Q}_{\mathrm{A}}{ }^{-}$couple in the $\triangle \mathrm{PsbJ}-43 \mathrm{H} / \mathrm{PSII}$, the effect of the DCMU binding could be negligible. Indeed, the Em of the $\mathrm{Q}_{\mathrm{A}} / \mathrm{Q}_{\mathrm{A}}{ }^{-}$couple with DCMU bound in the $\triangle \mathrm{PsbJ}-43 \mathrm{H} / \mathrm{PSII}$ would be the same than for the $\mathrm{Q}_{\mathrm{A}} / \mathrm{Q}_{\mathrm{A}}{ }^{-}$couple in the absence of DCMU in WT*1/PSII. A higher Em of the $\mathrm{Q}_{\mathrm{B}} / \mathrm{Q}_{\mathrm{B}}{ }^{-}$couple may also explain the lower $\mathrm{O}_{2}$ evolution under continuous illumination by the $\Delta \mathrm{PsbJ}$ 43H/PSII (Sugiura et al. 2010b) by decreasing the efficiency of the electron transfer between $\mathrm{QB}^{-}{ }^{-}$and the added quinone.

Alone, a low Em of the $\mathrm{Q}_{\mathrm{A}} / \mathrm{Q}^{-}{ }^{-}$couple in $\triangle \mathrm{PsbJ}-43 \mathrm{H} / \mathrm{PSII}$ is expected to increase the damages due to the repopulation of triplet states in the functional enzyme. For that reason we would favor the model in which only the $E m$ of the $\mathrm{Q}_{\mathrm{B}} / \mathrm{Q}_{\mathrm{B}}{ }^{-}$couple is affected (increased) in $\Delta \mathrm{PsbJ}-43 \mathrm{H} / \mathrm{PSII}$. The increase of the $\Delta E m$ between $\mathrm{Q}_{\mathrm{A}} / \mathrm{Q}_{\mathrm{A}^{-}}$and $\mathrm{Q}_{\mathrm{B}} / \mathrm{Q}_{\mathrm{B}}{ }^{-}$, and without affecting the forward electron transfer, could contribute in a protection against the charge recombinations between the donor side and $\mathrm{QB}^{-}$. Such a charge recombination was identified at the origin the damage by about 2 orders of magnitude higher than that induced by the same amount of energy delivered by continuous light (Keren et al. 1997) and a protection against it would favor the photoactivation process, see (Bao and Burnap 2016) for a recent review on photoactivation. 


\section{Legends of the figures}

Figure 1: Light-induced difference spectra around $545 \mathrm{~nm}$. The flash-induced absorption changes were measured in PsbA1/PSII (black spectrum), $\triangle \mathrm{PsbJ}-43 \mathrm{H} / \mathrm{PSII}$ (red spectrum) and PsbA3-PSII (blue spectrum). The data points are the average of the $\Delta \mathrm{I} / \mathrm{I}$ values detected $15 \mu \mathrm{s}$ after the $2^{\text {nd }}$ to $7^{\text {th }}$ actinic flashes given to dark-adapted PSII. After dark adaptation for $1 \mathrm{~h}$ at room temperature, $100 \mu \mathrm{M}$ PPBQ (dissolved in dimethyl sulfoxide) was added to the samples. The amplitude of the spectra were normalized to a Chl concentration corresponding to $\mathrm{OD}_{673 \mathrm{~nm}}=1.75$.

Figure 2: MALDI-TOF MS profiling of PSII subunits. (A) Linear mode MALDI-TOF spectra of subunits from $\Delta$ PsbJ-43H/PSII (upper panel) and WT*1-PSII (lower panel) strains. For presentation, both spectra were internally recalibrated on known peaks of PSII subunits using their theoretical average masses (formylated PsbT, $m / z=3902.67 \mathrm{Da}$; PsbK, $m / z=4099.88$ Da; PsbL, $m / z=4297.02 \mathrm{Da}$; acetylated PsbF, $m / z=4975.66 \mathrm{Da}$; formylated PsbZ, $m / z=$ 6792.18 Da; PsbE, $m / z=9441.53 \mathrm{Da}$ ) according to (Sugiura et al. 2010a 2010b, Boussac et al. 2013, Nowaczyk et al. 2012). In the inset, zoom of the $3090-4025 \mathrm{~m} / \mathrm{z}$ range of highresolution MALDI-TOF spectra from $\triangle \mathrm{PsbJ}-43 \mathrm{H} / \mathrm{PSII}$ mutant (upper panel) and WT*1-PSII wild-type (lower panel) strains acquired in reflection mode. Both spectra were internally recalibrated on known mono-isotopic peaks of PSII subunits using their theoretical monoisotopic masses (formylated PsbT, $m / z=3900.09 \mathrm{Da}$; PsbK, $m / z=4097.32 \mathrm{Da}$; PsbL, $m / z=$ 4294.32 Da; acetylated PsbF, $m / z=4972.61$ Da. (B) Linear mode MALDI-TOF spectra of $\triangle \mathrm{PsbJ}-43 \mathrm{H} / \mathrm{PSII}$ mutant (upper panel) and WT*1/PSII (lower panel) strains. In the upper panel which shows the $11000-15000 \mathrm{~m} / \mathrm{z}$ range for the $\Delta \mathrm{PsbJ}-43 \mathrm{H} / \mathrm{PSII}$ mutant spectrum, the amplitude was magnified 10 times. (*) this 206 Da mass shift could correspond to farnesyl adduct find in mono-charged and discharged PsbV. There is no peak at $16472 \mathrm{~m} / \mathrm{z}$ which suggests that the peak at $8236 \mathrm{~m} / \mathrm{z}$ does not correspond to a double charged ion. Instead, it could correspond to a contamination by the subunit c of the ATP synthase (Suhai et al. 2008).

Figure 3: Thermoluminescence curves after one flash given at $-10^{\circ} \mathrm{C}$ either without any addition (Panel A) or in the presence of DCMU (Panel B). Black curve, WT*1/PSII; red curve, $\triangle \mathrm{PsbJ}-43 \mathrm{H} / \mathrm{PSII}$. The concentration of the samples was adjusted exactly to $\mathrm{OD}_{673 \mathrm{~nm}}=0.7(\sim 10 \mu \mathrm{g} \mathrm{Chl} / \mathrm{mL})$ before to be dark-adapted at room temperature for at least $1 \mathrm{~h}$. 
In Panel B, the final concentration of DCMU, dissolved in ethanol, was $100 \mu \mathrm{M}$. After the addition of DCMU, the samples were immediately loaded into the cuvette in total darkness. The heating rate was $0.4^{\circ} \mathrm{C} / \mathrm{s}$.

Figure 4: EPR spectra recorded in WT*1-PSII and $\Delta$ PsbJ-43H/PSII. The spectra were recorded after dark-adaptation for 1 hour at room temperature (black spectra) and after a continuous illumination at $198 \mathrm{~K}$ (red spectra). The blue spectra are the light-minus-dark spectra. The concentration was $1.1 \mathrm{mg} \mathrm{Chl} / \mathrm{mL}$. Instrument settings: temperature, $8.6 \mathrm{~K}$; modulation amplitude, $25 \mathrm{G}$; microwave power, $20 \mathrm{~mW}$; microwave frequency, $9.4 \mathrm{GHz}$; modulation frequency, $100 \mathrm{kHz}$.

Figure 5: EPR spectra recorded in $\mathrm{WT}^{*} 1 / \mathrm{PSII}$ and $\Delta \mathrm{PsbJ}-43 \mathrm{H} / \mathrm{PSII}$. The spectra were recorded after dark-adaptation for 1 hour at room temperature (black spectra), after illumination by one flash at room temperature (green spectra) and after a further continuous illumination at $198 \mathrm{~K}$ (red spectra). The concentration was $1.1 \mathrm{mg} \mathrm{Chl} / \mathrm{mL}$. Instrument settings: temperature, $8.6 \mathrm{~K}$; microwave frequency, $9.4 \mathrm{GHz}$; modulation frequency, $100 \mathrm{kHz}$. Modulation amplitude, $25 \mathrm{G}$ and microwave power, $20 \mathrm{~mW}$ in Panel A and modulation amplitude, $2.8 \mathrm{G}$ and microwave power, $2 \mu \mathrm{W}$ in Panel B. In the conditions used for the recording of the $\operatorname{TyrD}^{\bullet}$ spectra, the microwave power is still slightly saturating so that an increase in the relaxation properties upon the formation of $S_{2}$ induces an increase of the signal amplitude (Styring and Rutherford 1988). This effect is larger in the negative part of the signal and is less when using a smaller modulation frequency (not shown) which is indicative of a rapid-passage effect (Styring and Rutherford 1988).

Figure 6: EPR spectra recorded in WT*1-PSII (Panel A) and $\Delta$ PsbJ-43H/PSII (Panel B). The spectra were recorded after dark-adaptation for 1 hour at room temperature (black spectra) and after the addition $(100 \mu \mathrm{M})$ dissolved in ethanol (red spectra). Then, the blue spectra were recorded after an illumination at $198 \mathrm{~K}$. The green spectra were recorded after a brief (1-2 s) warming of the samples at $0^{\circ} \mathrm{C}$ and the spectra in magenta were recorded after a second brief warming at $20^{\circ} \mathrm{C}$. The concentration was $1.1 \mathrm{mg} \mathrm{Chl} / \mathrm{mL}$. Instrument settings: temperature, 8.6 K; microwave frequency, $9.4 \mathrm{GHz}$; modulation frequency, $100 \mathrm{kHz}$; modulation amplitude, $25 \mathrm{G}$; microwave power, $20 \mathrm{~mW}$. 
Figure 7: Time-courses of the $\Delta \mathrm{I} / \mathrm{I}$ changes at $320 \mathrm{~nm}$ after the $2^{\text {nd }}$ flash given on dark-adapted WT*1-PSII (black points), $\Delta$ PsbJ-43H/PSII (red points) and WT*3-PSII (blue data points). Flashes spaced $300 \mathrm{~ms}$ apart. Chl concentration adjusted to $\mathrm{OD}_{673 \mathrm{~nm}}=1.75$.

Figure 8: EPR spectra recorded in WT*1-PSII (black spectra) and $\Delta$ PsbJ-43H/PSII (red spectra). Panel A, the spectra were recorded after dark-adaptation for 1 hour at room temperature. Panel B, the spectra were recorded after a further illumination at $4.2 \mathrm{~K}$. Panel C, the spectra were recorded after the addition of $100 \mu \mathrm{M}$ of ferricyanide on dark-adapted samples followed by an illumination at $4.2 \mathrm{~K}$. Panel D, the spectra were recorded after the addition of DCMU $(100 \mu \mathrm{M})$ dissolved in ethanol to dark-adapted samples. The concentration was $1.1 \mathrm{mg} \mathrm{Chl} / \mathrm{mL}$. Instrument settings: temperature, $4.2 \mathrm{~K}$ except for Panel A in which $\mathrm{T}=$ $8.6 \mathrm{~K}$; microwave frequency, $9.4 \mathrm{GHz}$; modulation frequency, $100 \mathrm{kHz}$; modulation amplitude, $25 \mathrm{G}$; microwave power, $20 \mathrm{~mW}$. 


\section{References}

Bao H, Burnap RL (2016) Photoactivation: The light-driven assembly of the water oxidation complex of Photosystem II. Front Plant Sci 7:article 578.

https://doi.org/10.3389/fpls.2016.00578

Beal D, Rappaport F, Joliot P (1999) A new high-sensitivity 10-ns time-resolution spectrophotometric technique adapted to in vivo analysis of the photosynthetic apparatus. Rev Sci Instrum 70: 202-207. https://doi.org/10.1063/1.1149566

Boussac A, Sugiura M, Rappaport F (2011) Probing the quinone binding site of photosystem II from Thermosynechococcus elongatus containing either PsbA1 or PsbA3 as the D1 protein through the binding characteristics of herbicides. Biochim Biophys Acta 1807:119-129. https://doi.org/10.1016/j.bbabio.2010.10.004

Broser M, Gabdulkhakov A, Kern J, Guskov A, Muh F, Saenger W, Zouni A (2010) Crystal structure of monomeric Photosystem II from Thermosynechococcus elongatus at 3.6- $\mathrm{A}^{\circ}$ resolution. J Biol Chem 285: 26255-26262. https://doi.org/10.1074/jbc.M110.127589.

Choo P, Forsman JA, Hui LL, Khaing EP, Summerfield TC, Eaton-Rye JJ (2021) The PsbJ protein is required for photosystem II activity in centers lacking the PsbO and PsbV lumenal subunits. Photosynth Res, early access. https://doi.org/10.1007/s11120-021-00862-y

Cox N, Pantazis DA, Lubitz W (2020) Current understanding of the mechanism of water oxidation in Photosystem II and its relation to XFEL data. Annu. Rev. Biochem. 89:795-820. https://doi.org/10.1146/annurev-biochem-011520-104801

Cser K, Vass I (2007) Radiative and non-radiative charge recombination pathways in Photosystem II studied by thermoluminescence and chlorophyll fluorescence in the cyanobacterium Synechocystis 6803. Biochim Biophys Acta 1767: 233-243.

https://doi.org/10.1016/j.bbabio.2007.01.022

Cuni A, Xiong L, Sayre R, Rappaport F, Lavergne J (2004) Modification of the pheophytin midpoint potential in Photosystem II: modulation of the quantum yield of charge separation and of charge recombination pathways. Phys Chem Chem Phys 6: 4825-4831 https://doi.org/10.1039/B407511K 
de Causmaecker S, Douglass JS, Fantuzzi A, Nitschke W, Rutherford AW (2019) Energetics of the exchangeable quinone, Qв, in Photosystem II. Proc Natl Acad Sci USA 116: 1945819463. www.pnas.org/cgi/doi/10.1073/pnas.1910675116

Demeter S, Goussias C, Bern G, Kovács L, Petrouleas V (1993) Participation of the $g=1.9$ and $g=1.82 \mathrm{EPR}$ forms of the semiquinone-iron complex, $\mathrm{Q}_{\mathrm{A}} \mathrm{Fe}^{2+}$ of photosystem II in the generation of the Q and $\mathrm{C}$ thermoluminescence bands, respectively. FEBS 336: 352-356. https://doi.org/10.1016/0014-5793(93)80836-J

Diner BA, Petrouleas V (1987) Light-induced oxidation of the acceptor-side Fe(11) of Photosystem II by exogenous quinones acting through the $\mathrm{Q}_{в}$ binding site. II. Blockage by inhibitors and their effects on the FeIII) EPR spectra. Biochim Biophys Acta 893: 138-148. https://doi.org/10.1016/0005-2728(87)90033-8

Ducruet JM (2003) Chlorophyll thermoluminescence of leaf discs: simple instruments and progress in signal interpretation open the way to new ecophysiological indicators. J Exp Bot 54: 2419-2430. https://doi.org/10.1093/jxb/erg268

Ducruet JM, Vass I (2009) Thermoluminescence: experimental. Photosynth Res 201: 195204. https://doi.org/10.1007/s11120-009-9436-0

Forsman JA, Eaton-Rye JJ (2021) The interaction between PsbT and the DE loop of D1 in Photosystem II stabilizes the quinone-iron electron acceptor complex. Biochemistry 60: 5363. https://doi.org/10.1021/acs.biochem.0c00668.

Fufezan C, Zhang CX, Krieger-Liszkay A, Rutherford AW (2005) Secondary quinone in photosystem II of Thermosynechococcus elongatus: semiquinone-iron EPR signals and temperature dependence of electron transfer. Biochemistry 44: 12780-12789. https://doi.org/10.1021/bi051000k

Funk C (2000) Functional analysis of the PsbX protein by deletion of the corresponding gene in Synechocystis sp. PCC 6803. Plant Mol Biol 44: 815-827. https://doi.org/10.1023/A:1026764728846

Garcia-Cerdan JG, Sveshnikov D, Dewez D, Jansson S, Funk C, Schroder WP (2009) Antisense inhibition of the PsbX protein affects PSII integrity in the higher plant Arabidopsis thaliana. Plant Cell Physiol 50: 191-202. https://doi.org/10.1093/pcp/pcn188 
Holzwarth AR, Müller MG, Reus M, Nowaczyk M, Sander J, Rögner M (2006) Kinetics and mechanism of electron transfer in intact photosystem II and in the isolated reaction center: pheophytin is the primary electron acceptor. Proc Natl Acad Sci USA 103: 6895-6900. https://doi.org/10.1073/pnas.0505371103

Huang G, Xiao Y, Pi X, Zhaoa L, Zhu Q, Wang W, Kuang T, Han G, Sui S-F, Shen J-R (2021) Structural insights into a dimeric Psb27-photosystem II complex from a cyanobacterium Thermosynechococcus vulcanus. Proc Natl Acad Sci USA 118: e2018053118. https://doi.org/10.1073/pnas.2018053118

Hughes JL, Cox N, Rutherford AW, Krausz E, Lai T-L, Boussac A, Sugiura M (2010) D1 protein variants in Photosystem II from Thermosynechococcus elongatus studied by low temperature optical spectroscopy. Biochim Biophys Acta 1797: 11-19. https://doi.org/10.1016/j.bbabio.2009.07.007

Inoue-Kashino N, Kashino Y, Takahashi Y (2011) Psb30 is a photosystem II reaction center subunit and is required for optimal growth in high light in Chlamydomonas reinhardtii. J Photochem Photobiol 104: 220-228. https://doi.org/10.1016/j.jphotobiol.2011.01.024

Ishida N, Sugiura M, Rappaport F, Lai T-L, Rutherford AW, Boussac A (2008) Biosynthetic exchange of bromide for chloride and strontium for calcium in the photosystem II oxygenevolving enzyme. J Biol Chem 283: 13330-13340. https://doi.org/10.1074/jbc.M710583200

Iwai M, Suzuki T, Kamiyama A, Sakurai I, Dohmae N, Inoue Y, Ikeuchi M (2010) The PsbK subunit is required for the stable assembly and stability of other small subunits in the PSII complex in the thermophilic cyanobacterium Thermosynechococcus elongatus BP-1. Plant Cell Physiol 51: 554-560. https://doi.org/10.1093/pcp/pcq020

Johnson GN, Rutherford AW, Krieger A (1995) A change in the midpoint potential of the quinone QA in Photosystem II associated with photoactivation of oxygen evolution. Biochim Biophys Acta 1229: 202-207. https://doi.org/10.1016/0005-2728(95)00003-2

Joliot P, Kok B (1975) Oxygen evolution in photosynthesis, in: Govindjee (Ed.), Bioenergetics of Photosynthesis, Academic Press, New York, pp. 387-412.

Kaminskaya O, Shuvalov VA, Renger G (2007) Evidence for a novel quinone-binding site in the photosystem II (PS II) complex that regulates the redox potential of cytochrome b559. Biochemistry 46: 1091-1105. https://doi.org/10.1134/S1607672907010048 
Kashino Y, Lauber WM, Carroll JA, Wang Q, Whitmarsh J, Satoh K, Pakrasi HB (2002) Proteomic analysis of a highly active photosystem II preparation from the cyanobacterium Synechocystis sp. PCC 6803 reveals the presence of novel polypeptides. Biochemistry 41: 8004-8012. https://10.1021/bi026012

Kashino Y, Takahashi T, Inoue-Kashino N, Ban A, Ikeda Y, Satoh K, Sugiura M (2007) Ycf12 is a core subunit in the photosystem II complex. Biochim Biophys Acta 1767: 12691275. https://doi.org/10.1016/j.bbabio.2007.08.008

Keren N, Berg A, VanKan PJM, Levanon H, Ohad I (1997) Mechanism of photosystem II photoinactivation and D1 protein degradation at low light: The role of back electron flow. Proc Natl Acad Sci USA 94: 1579-1584. https://doi.org/10.1073/pnas.94.4.1579.

Kok B, Forbush B, McGloin M (1970) Cooperation of charges in photosynthetic $\mathrm{O}_{2}$ evolution-I. A linear four step mechanism. Photochem Photobiol 11: 457-475. https://doi.org/10.1111/j.1751-1097.1970.tb06017.x

Komenda J, Sobotka R, Nixon PJ (2012) Assembling and maintaining the Photosystem II complex in chloroplasts and cyanobacteria. Curr Opin Plant Biol 15: 245-251; https://doi.org/10.1016/j.pbi.2012.01.017

Krieger A, Rutherford AW, Johnson GN (1995) On the determination of redox midpoint potential of the primary quinone electron acceptor, $\mathrm{Q}_{\mathrm{A}}$, in photosystem II. Biochim Biophys Acta 1229:193-201. https://doi.org/10.1016/0005-2728(95)00002-Z

Lavergne J (1991) Improved UV-visible spectra of the S-transitions in the photosynthetic oxygen-evolving system. Biochim Biophys Acta 1060: 175-188.

https://doi.org/10.1016/S0005-2728(09)91005-2

Liu HJ, Chen JW, Huang RYC, Weisz D, Gross ML, Pakrasi HB (2013) Mass Spectrometrybased Footprinting Reveals Structural Dynamics of Loop E of the Chlorophyll-binding Protein CP43 during Photosystem II Assembly in the Cyanobacterium Synechocystis 6803. J Biol Chem 288: 14212-14220. https://doi.org/10.1074/jbc.M113.467613

Luo H, Jackson SA, Fagerlund RD, Summerfield TC, Eaton-Rye JJ (2014) The importance of the hydrophilic region of PsbL for the plastoquinone electron acceptor complex of Photosystem II. Biochim Biophys Acta 1837: 1435-1446.

https://doi.org/10.1016/j.bbabio.2014.02.015 
Merry SAP, Nixon PJ, Barter LMC, Schilstra MJ, Porter G, Barber J, Durrant JR, Klug D (1998) Modulation of quantum yield of primary radical pair formation in photosystem II by site directed mutagenesis affecting radical cations and anions. Biochemistry 37: 1743917447. https://doi.org/10.1021/bi980502d

Müh F, Zouni A (2005) Extinction coefficients and critical solubilisation concentrations of photosystems I and II from Thermosynechococcus elongatus. Biochim Biophys Acta 1708: 219-228. https://doi.org/10.1016/j.bbabio.2005.03.005

Müh F, Glöckner C, Hellmich J, Zouni A (2012) Light-induced quinone reduction in photosystem II. Biochim Biophys Acta 1817: 44-65.

https://doi.org/10.1016/j.bbabio.2011.05.021

Mulo P, Sicora C, Aro E-M (2009) Cyanobacterial psbA gene family: optimization of oxygenic photosynthesis. Cell Mol Life Sci 66: 3697-3710. https://doi.org/10.1007/s00018009-0103-6

Nowaczyk MM, Hebeler R, Schlodder E, Meyer HE, Warscheid B, Rogner M (2006) Psb27, a cyanobacterial lipoprotein, is involved in the repair cycle of photosystem II. Plant Cell 18: 3121-3131. https://doi.org/10.1105/tpc.106.042671

Nowaczyk MM, Krause K, Mieseler M, Sczibilanski A, Ikeuchi M, Rögner M (2012) Deletion of psbJ leads to accumulation of Psb27-Psb28 photosystem II complexes in Thermosynechococcus elongatus. Biochim Biophys Acta 1817: 1339-1345.

http://dx.doi.org/10.1016/j.bbabio.2012.02.017

Ohad I, Dal Bosco C, Herrmann RG, Meurer J (2004) Photosystem II proteins PsbL and PsbJ regulate electron flow to the plastoquinone pool. Biochemistry 43: 2297-2308.

https://doi.org/10.1021/bi0348260

Rappaport F, Lavergne J (2009) Thermoluminescence: theory. Photosynth Res 101:205-216. https://doi.org/10.1007/s11120-009-9437-z

Regel RE, Ivleva NB, Zer H, Meurer J, Shestakov SV, Herrmann RG, Pakrasi HB, Ohad I (2001) Deregulation of electron flow within Photosystem II in the absence of the PsbJ protein. J Biol Chem 276: 41473-41478. https://doi.org/10.1074/jbc.M102007200 
Romero E, Novoderezhkin VI, van Grondelle R (2017) Quantum design of photosynthesis for bio-inspired solar-energy conversion. Nature 543: 355-365.

https://doi.org/10.1038/nature22012

Roncel M, Boussac A, Zurita JL, Bottin H, Sugiura M, Kirilovsky D, Ortega J-M (2003)

Redox properties of the photosystem II cytochromes b559 and c550 in the cyanobacterium Thermosynechococcus elongatus. J Biol Inorg Chem 8: 206-216.

https://doi.org/10.1007/s00775-002-0406-7

Roose JL, Pakrasi HB (2008) The Psb27 protein facilitates manganese cluster assembly in photosystem II. J Biol Chem 283:4044-4050. https://doi.org/10.1074/jbc.M708960200

Roose JL, Frankel LK, Mummadisetti MP, Bricker TM (2016) The extrinsic proteins of photosystem II: update. Planta 243: 889-908. https://doi.org/10.1007/s00425-015-2462-6

Rutherford AW, Crofts AR, Inoue Y (1982) Thermoluminescence as a probe of Photosystem II photochemistry. The origin of the flash-induced glow peaks. Biochim Biophys Acta 682: 457-465. https://doi.org/10.1016/0005-2728(82)90061-5

Rutherford AW, Zimmermann J-L (1984) A new EPR signal attributed to the primary plastosemiquinone acceptor in Photosystem II. Biochim Biophys Acta 767: 168-175. https://doi.org/10.1016/0005-2728(84)90092-6

Rutherford AW, Zimmermann J-L, Mathis P (1983) The effect of herbicides on components of the PS II reaction centre measured by EPR. Febs lett 165: 156-162.

https://doi.org/10.1016/0014-5793(84)80161-1

Rutherford AW, Krieger-Liszkay A (2001) Herbicide-induced oxidative stress in photosystem II. Trends Biochem Sci 26: 648-653. https://doi.org/10.1016/S0968-0004(01)01953-3

Sedoud A, Cox N, Sugiura M, Lubitz W, Boussac A, Rutherford AW (2011) The semiquinone-iron complex of Photosystem II: EPR signals assigned to the low field edge of the ground state doublet of $\mathrm{Q}_{\mathrm{A}}{ }^{-}-\mathrm{Fe}^{2+}$ and $\mathrm{Q}_{\mathrm{B}}{ }^{-}-\mathrm{Fe}^{2+}$. Biochemistry 50: 6012-6021. $\underline{\text { https://doi.org/10.1021/bi200313p }}$

Schatz GH, van Gorkom HJ (1985) Absorbance difference spectra upon charge transfer to secondary donors and acceptors in Photosystem II, Biochim Biophys Acta 810: 283-294. https://doi.org/10.1016/0005-2728(85)90212-9 
Shen JR (2015) The structure of Photosystem II and the mechanism of water oxidation in photosynthesis. Annu Rev Plant Biol 66: 23-48. https://doi.org/10.1146/annurev-arplant$\underline{050312-120129}$

Shen J-R, Qian M, Inoue Y, Burnap RL (1998) Functional characterization of Synechocystis sp. PCC $6803 \Delta$ psbU and $\Delta$ psbV mutants reveals important roles of cytochrome c-550 in cyanobacterial oxygen evolution. Biochemistry 37: 1551-1558.

https://doi.org/10.1021/bi971676i

Sheridan KJ, Duncan EJ, Eaton-Rye JJ, Summerfield TC (2020) The diversity and distribution of D1 proteins in cyanobacteria. Photosynth Res 145: 111-128. https://doi.org/10.1007/s11120-020-00762-7

Shibuya Y, Takahashi R, Okubo T, Suzuki H, Sugiura M, Noguchi T (2010) Hydrogen bond interaction of the pheophytin electron acceptor and its radical anion in Photosystem II as revealed by Fourier Transform Infrared Difference Spectroscopy. Biochemistry 49: 493-501. https://doi.org/10.1021/bi9018829

Styring S, Rutherford AW (1987) In the oxygen-evolving complex of photosystem II the $\mathrm{S}_{0}$ -

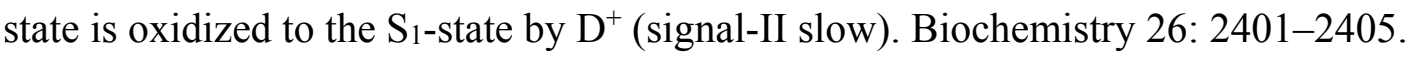
https://doi.org/10.1021/bi00383a001

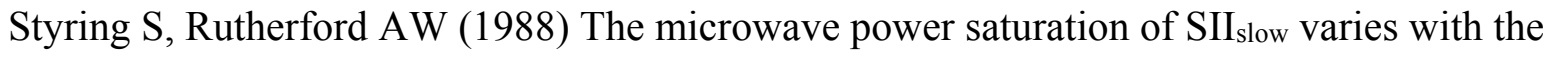
redox state of the oxygen-evolving complex in photosystem II. Biochemistry 27: 4915-4923. https://doi.org/10.1021/bi00413a049.

Suga M, Akita F, Hirata K, Ueno G, Murakami H, Nakajima Y, Shimizu T, Yamashita K, Yamamoto M, Ago H, Shen J-R (2015) Native structure of photosystem II at 1.95 angstrom resolution viewed by femtosecond X-ray pulses. Nature 517: 99-103.

https://doi.org/10.1038/nature13991

Sugiura M, Rappaport F, Brettel K, Noguchi T, Rutherford AW, Boussac A (2004) Sitedirected mutagenesis of Thermosynechococcus elongatus photosystem II: the $\mathrm{O}_{2}$ evolving enzyme lacking the redox active tyrosine D. Biochemistry 43: 13549-13563. https://doi.org/10.1021/bi048732h 
Sugiura M, Boussac A (2014) Some Photosystem II properties depending on the D1 protein variants in Thermosynechococcus elongatus. Biochim Biophys Acta 1837: 1427-1434. https://doi.org/10.1016/j.bbabio.2013.12.011

Sugiura M, Inoue Y (1999) Highly purified thermo-stable oxygen evolving Photosystem II core complex from the thermophilic cyanobacterium Synechococcus elongatus having Histagged CP43. Plant Cell Physiol 40: 1219-1231.

https://doi.org/10.1093/oxfordjournals.pcp.a029510

Sugiura M, Harada S, Manabe T, Hayashi H, Kashino Y, Boussac A (2010a) Psb30 contributes to structurally stabilise the Photosystem II complex in the thermophilic cyanobacterium Thermosynechococcus elongatus. Biochim Biophys Acta 1797: 1546-1554. https://doi.org/10.1016/j.bbabio.2010.03.020

Sugiura M, Iwai E, Hayashi H, Boussac A (2010b) Differences in the interactions between the subunits of Photosystem II dependent on D1 protein variants in the thermophilic cyanobacterium Thermosynechococcus elongatus. J Biol Chem 285: 30008-30018. https://doi.org/10.1074/jbc.M110.136945

Sugiura M, Azami C, Koyama K, Rutherford AW, Rappaport F, Boussac A (2014) Modification of the pheophytin redox potential in Thermosynechococcus elongatus Photosystem II with PsbA3 as D1. Biochim Biophys Acta 1837: 139-148.

https://doi.org/10.1016/j.bbabio.2013.09.009

Suhai T, Dencher NA, Poetsch A, Seelert H (2008) Remarkable stability of the proton translocating F1F0-ATP synthase from the thermophilic cyanobacterium Thermosynechococcus elongatus BP-1. Biochim Biophys Acta 1778: 1131-1140. https://doi.org/10.1016/j.bbamem.2007.12.017

Takasaka K, Iwai M, Umena Y, Kawakami K, Ohmori Y, Ikeuchi M, Takahashi Y, Kamiya N, Shen JR (2010) Deletion Structural and functional studies on Ycf12 (Psb30) and PsbZdeletion mutants from a thermophilic cyanobacterium. Biochim Biophys Acta 1797: 278-284. https://doi.org/10.1016/j.bbabio.2009.11.001

Umena Y, Kawakami K, Shen J-R, Kamiya N (2011) Crystal structure of oxygen-evolving Photosystem II at a resolution of 1.9 angstrom. Nature 473: 55-60.

https://doi.org/10.1038/nature09913 
Uto S, Kawakami K, Umena Y, Iwai M, Ikeuchi M, Shen JR, Kamiya N (2017) Mutual relationships between structural and functional changes in a PsbM-deletion mutant of photosystem II. Faraday Discuss198: 107-120. https://doi.org/10.1039/C6FD00213G

van Eerden FJ, Melo MN, Frederix PWJM, Periole X, Marrink SJ (2017) Exchange pathways of plastoquinone and plastoquinol in the photosystem II complex. Nature Comm 8:15214. https://doi.org/10.1038/ncomms15214

Velthuys BR (1981) Electron-dependent competition between plastoquinone and inhibitors for binding to Photosystem-II. Feb let 126: 277-281. https://doi.org/10.1016/0014$\underline{5793(81) 80260-8}$

Xiao Y, Huang G, You X, Zhu Q, Wang W, Kuang T, Han G, Sui S-F, Shen J-R (2021) Structural insights into cyanobacterial photosystem II intermediates associated with Psb28 and Ts10063. Nature Plants, early access. https://doi.org/10.1038/s41477-021-00961-7

Zabret J, Bohn S, Schuller SK, Arnolds O, Möller M, Meier-Credo J, Liauw P, Chan A, Tajkhorshid E, Langer JD, Stoll R, Krieger-Liszkay A, Engel BD, Rudack T, Schuller JM, Nowaczyk MM (2021) Structural insights into photosystem II assembly. Nature Plants 7:

524-538. https://doi.org/10.1038/s41477-021-00895-0 


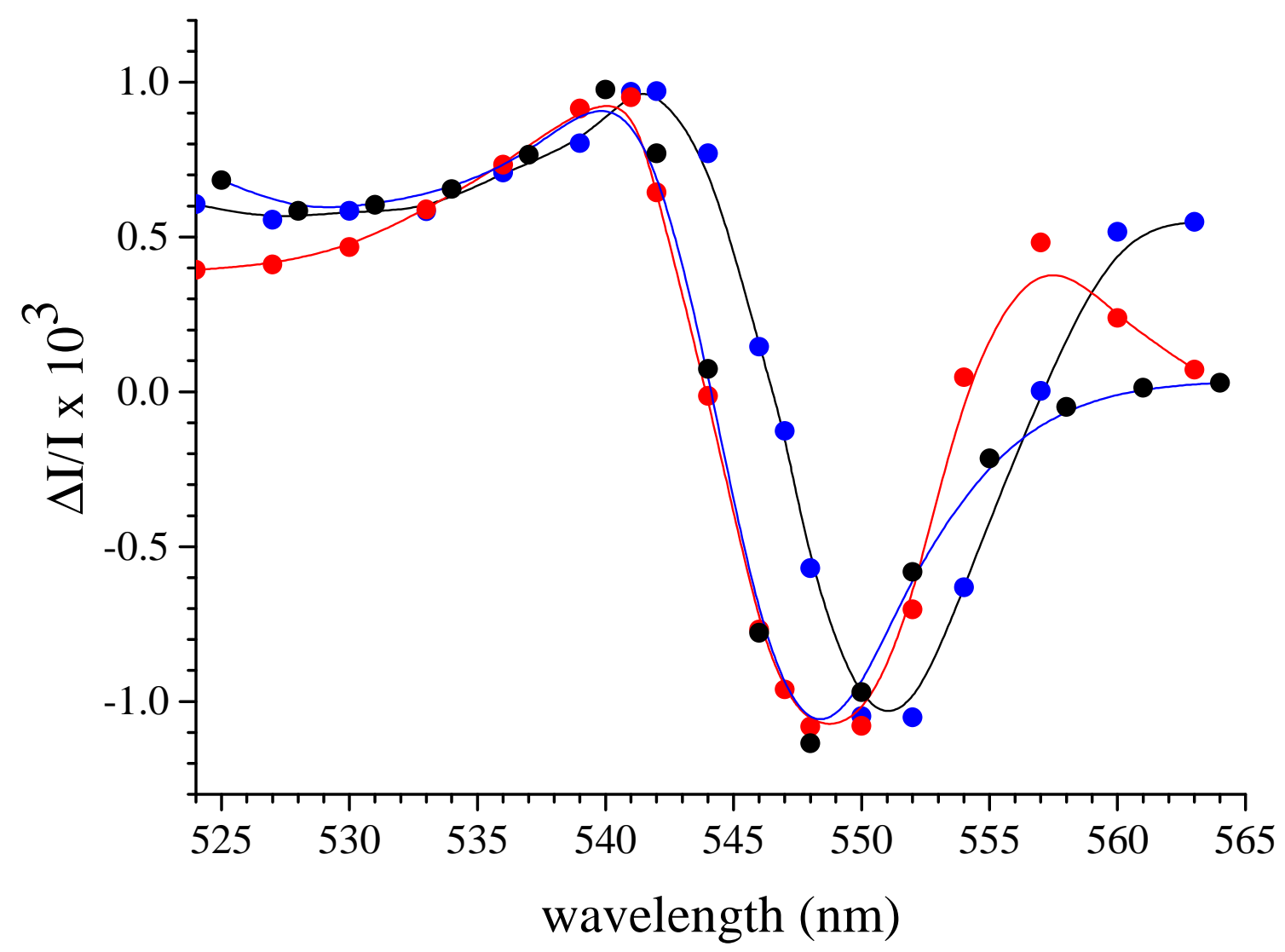

Fig. 1 
A
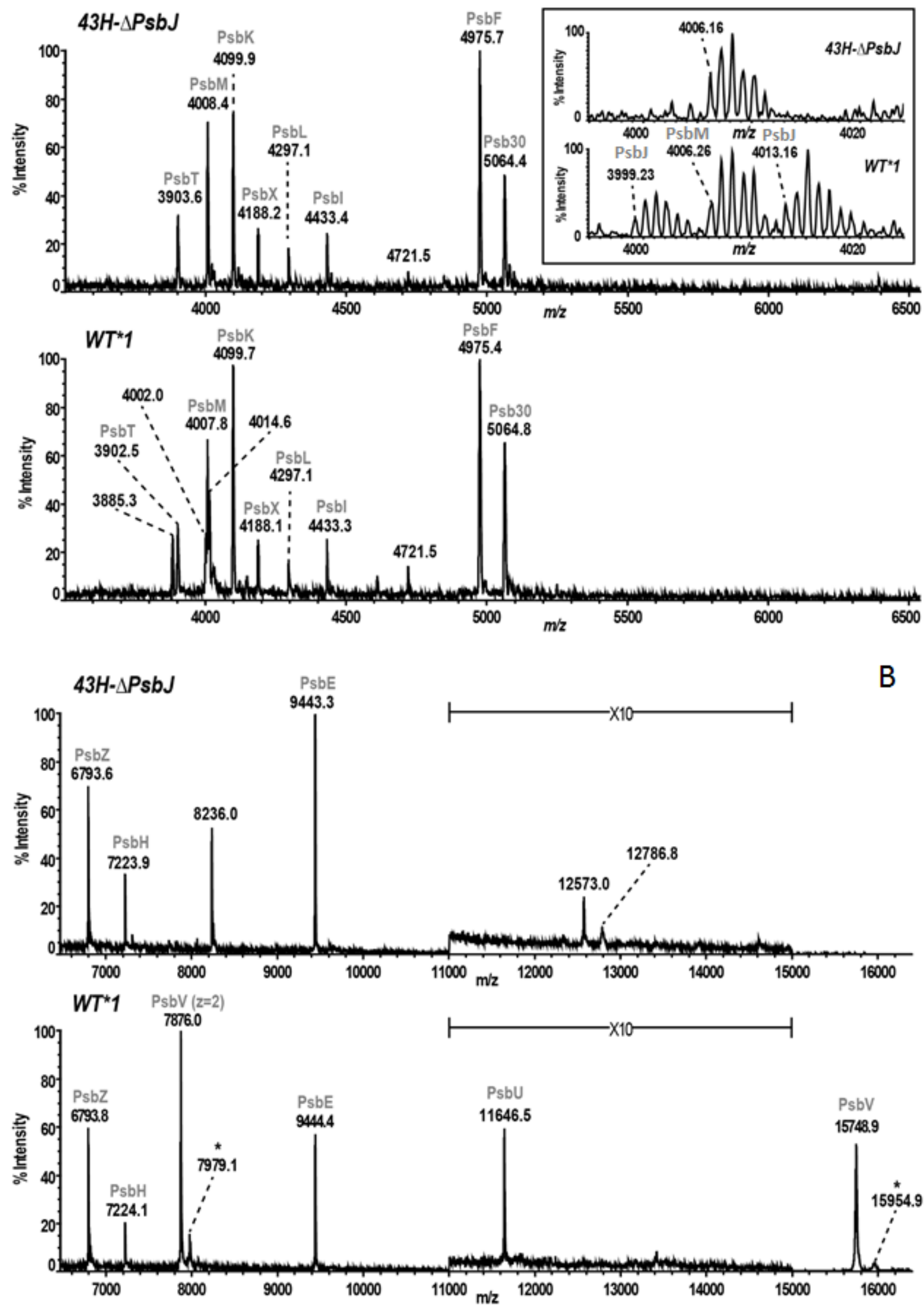

Fig. 2 

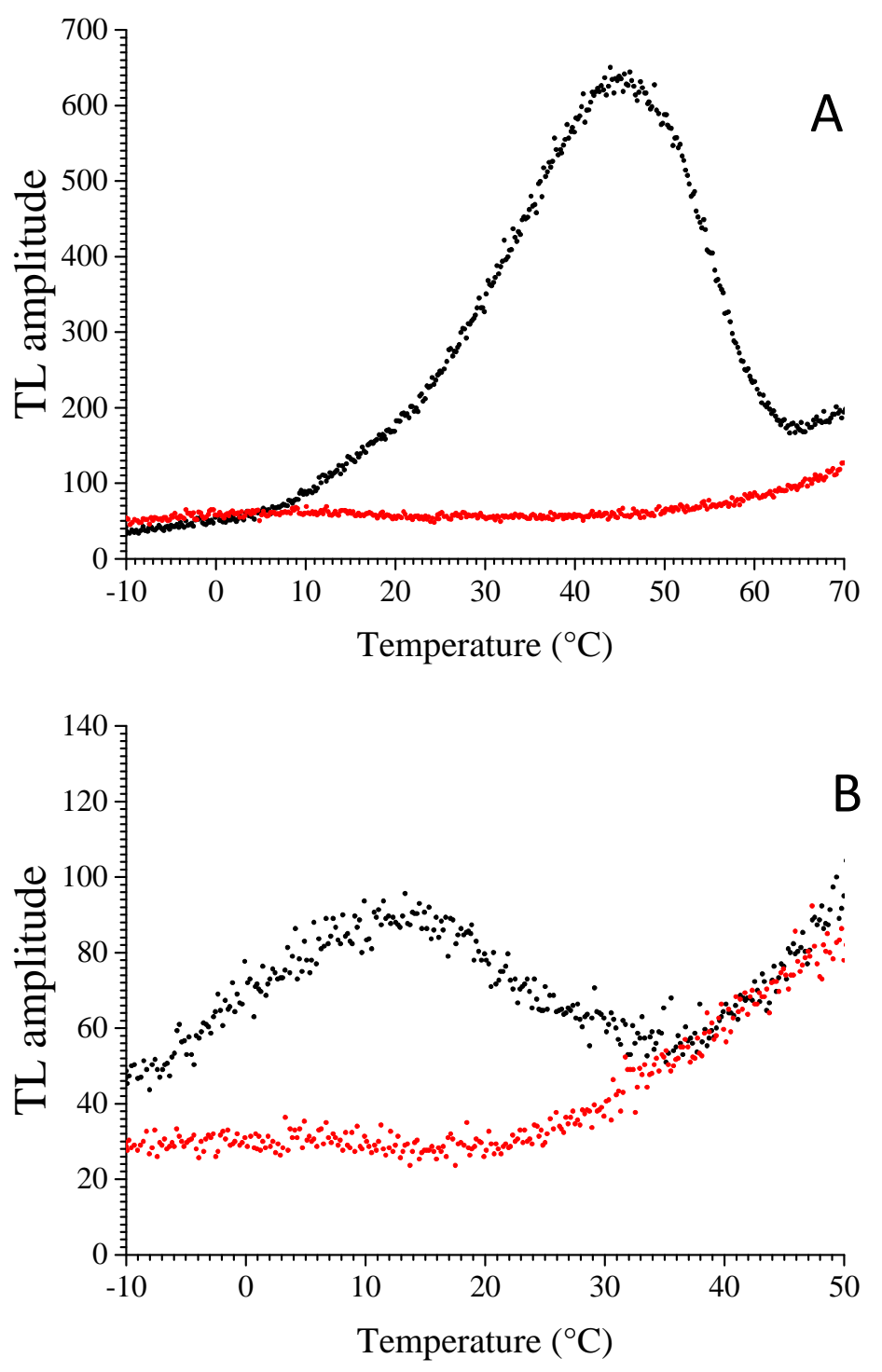

Fig. 3 


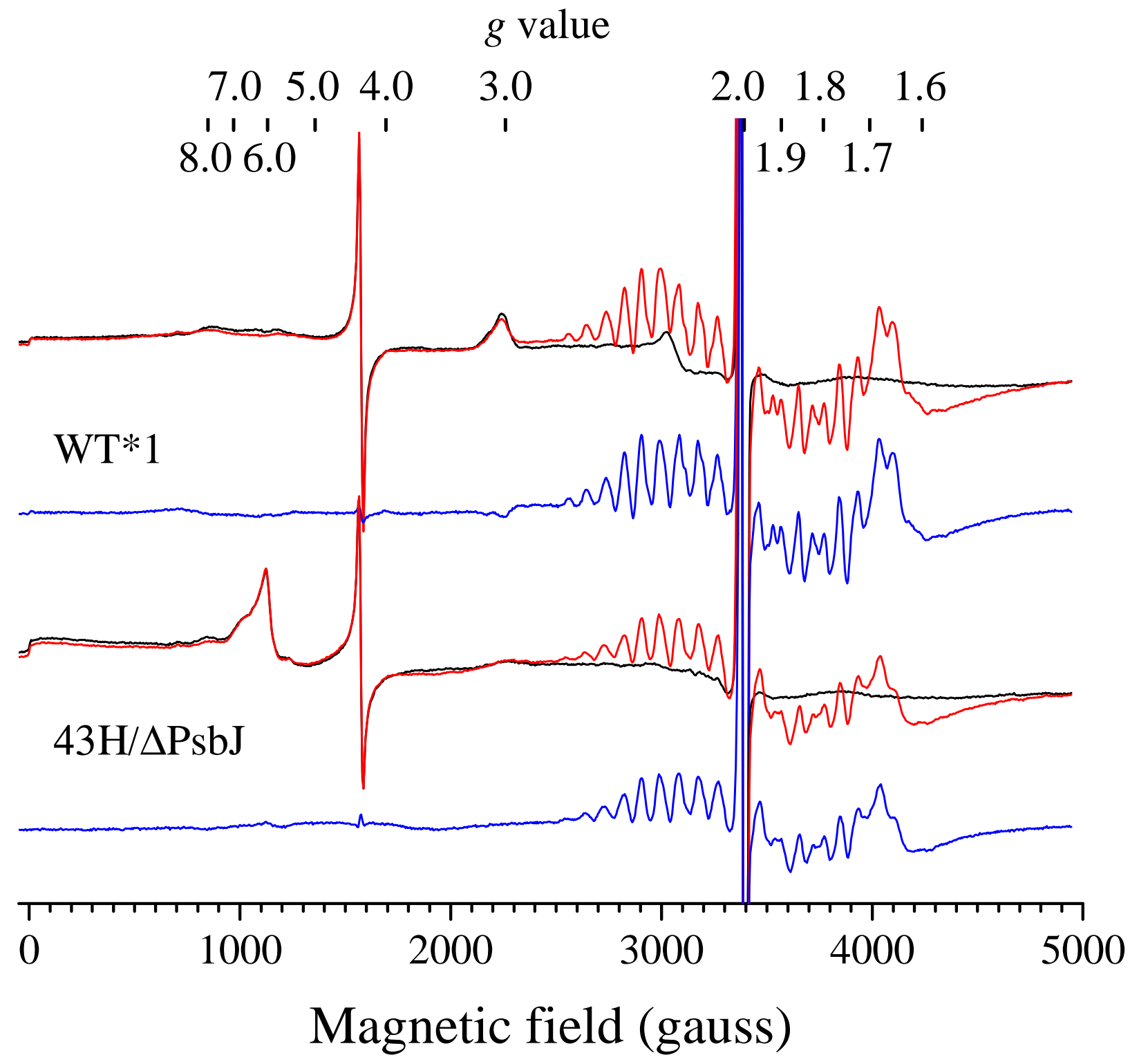

Fig. 4 

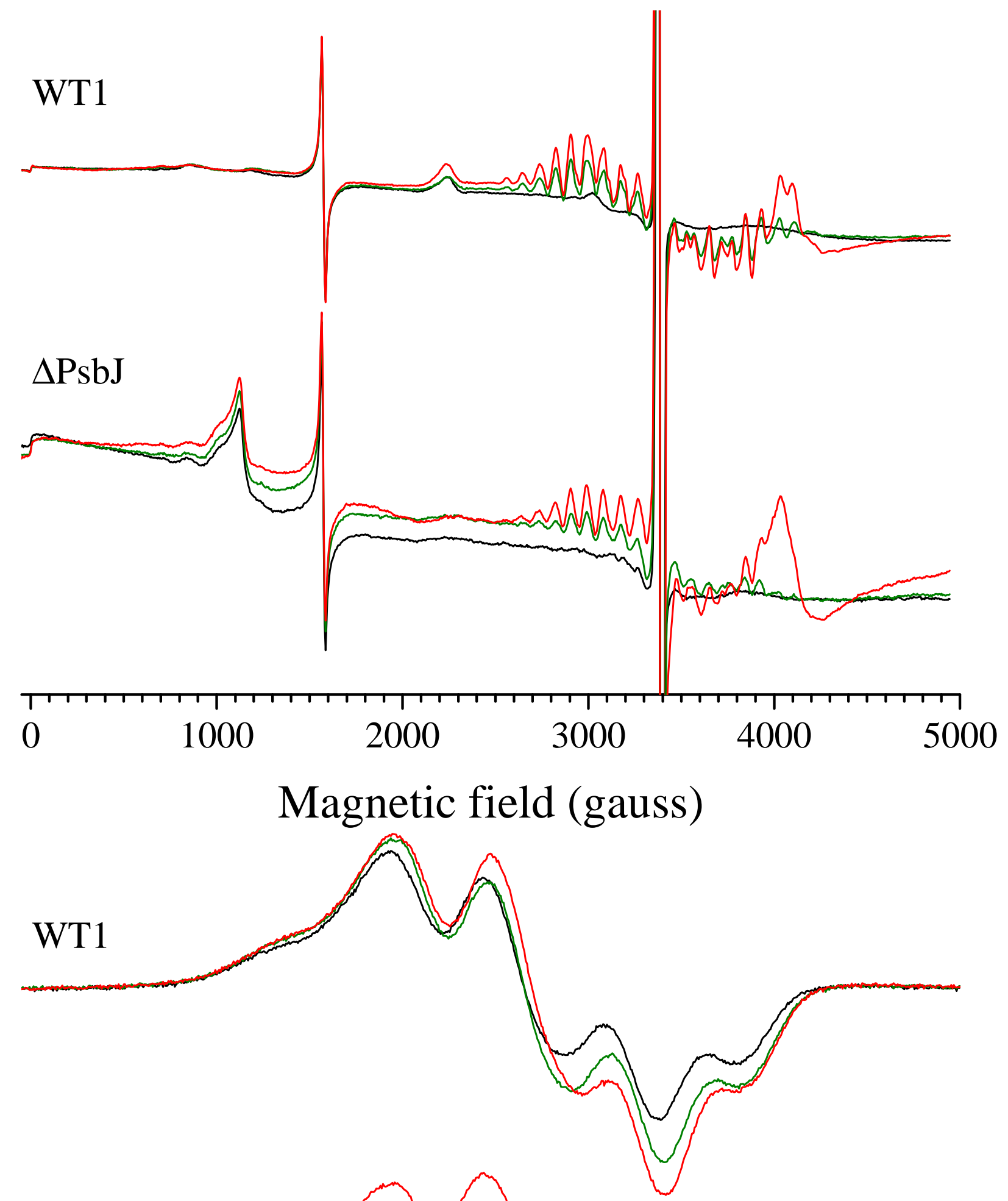

$\Delta \mathrm{PsbJ}$ 

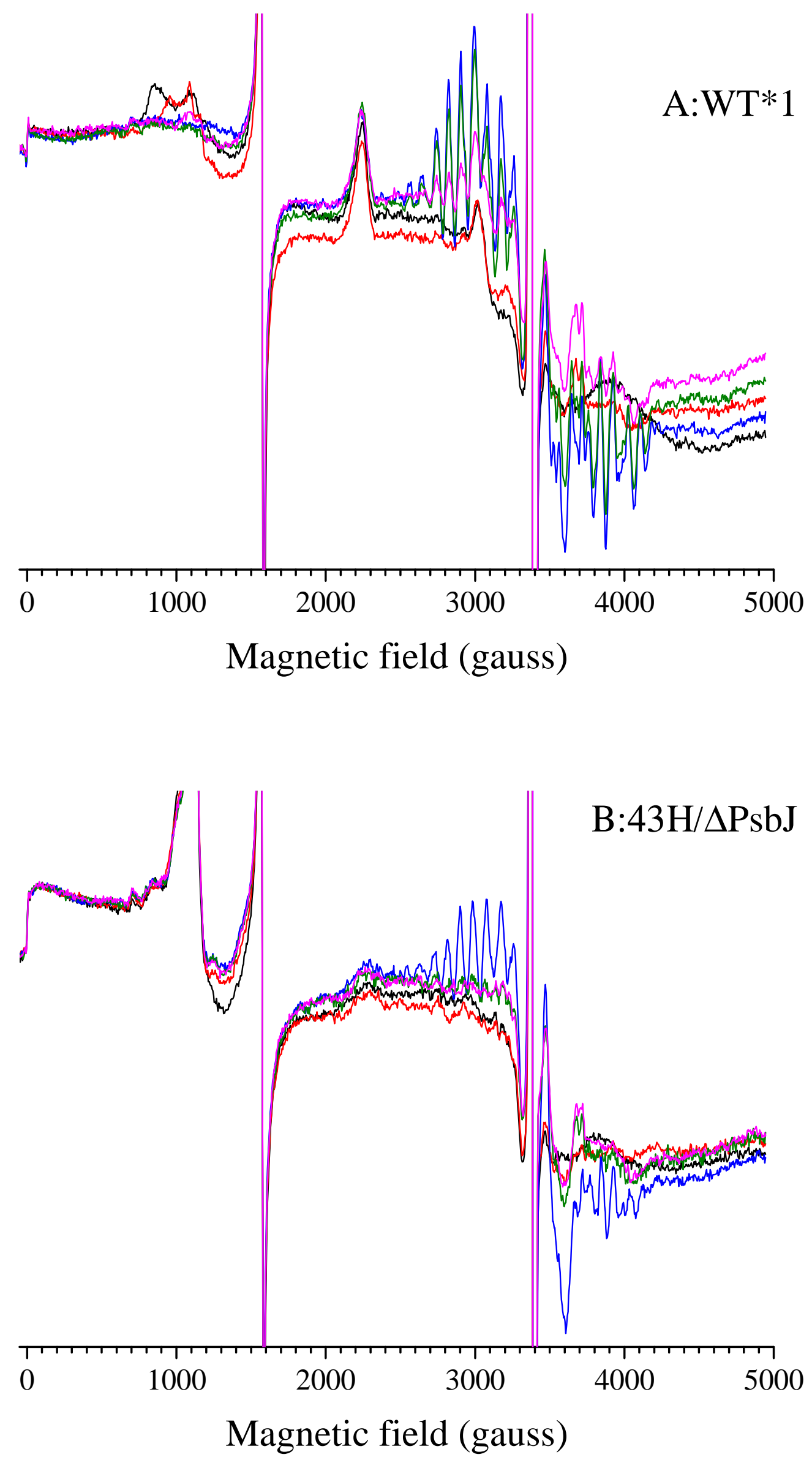

Fig. 6 


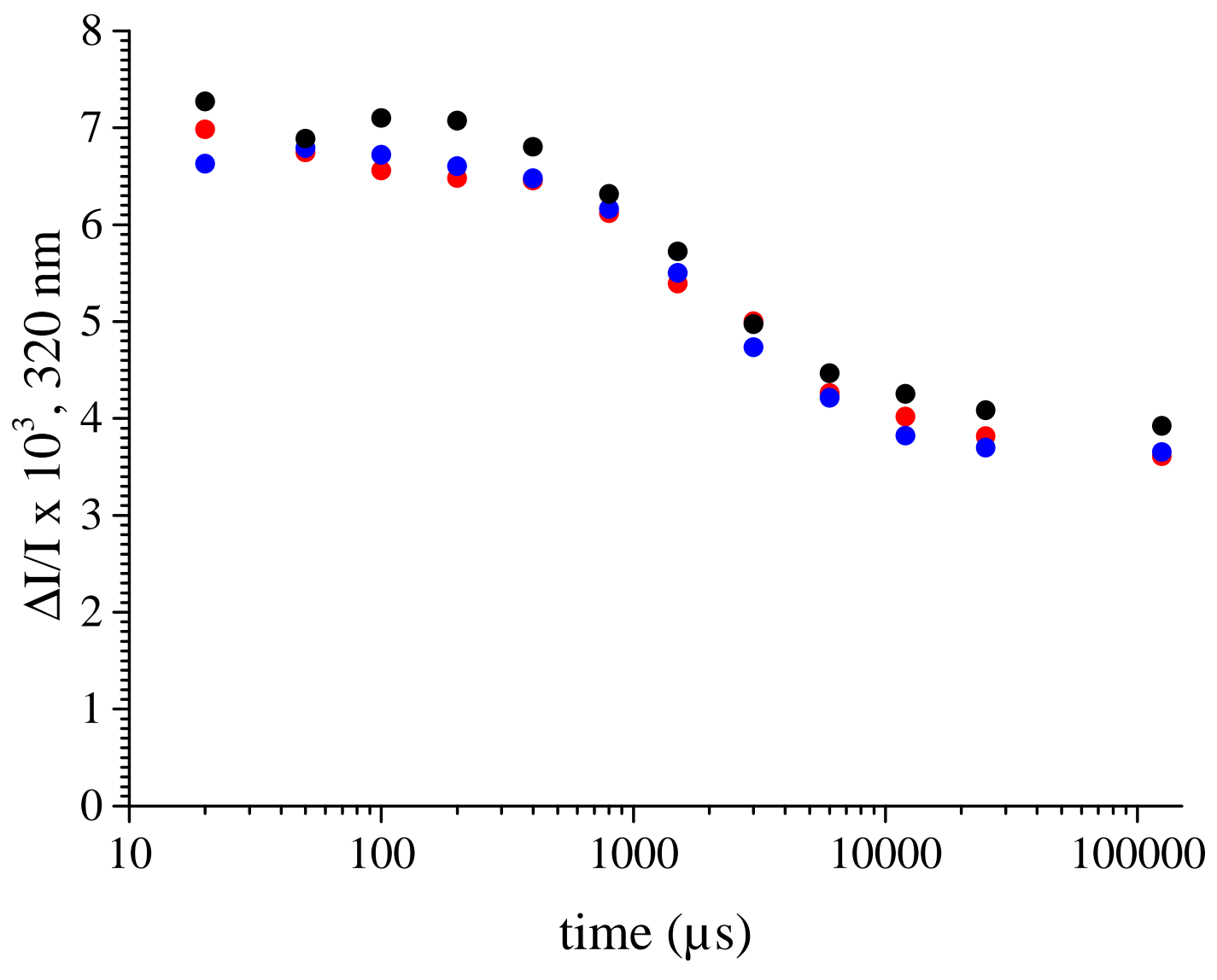

Fig. 7 
$g$ value

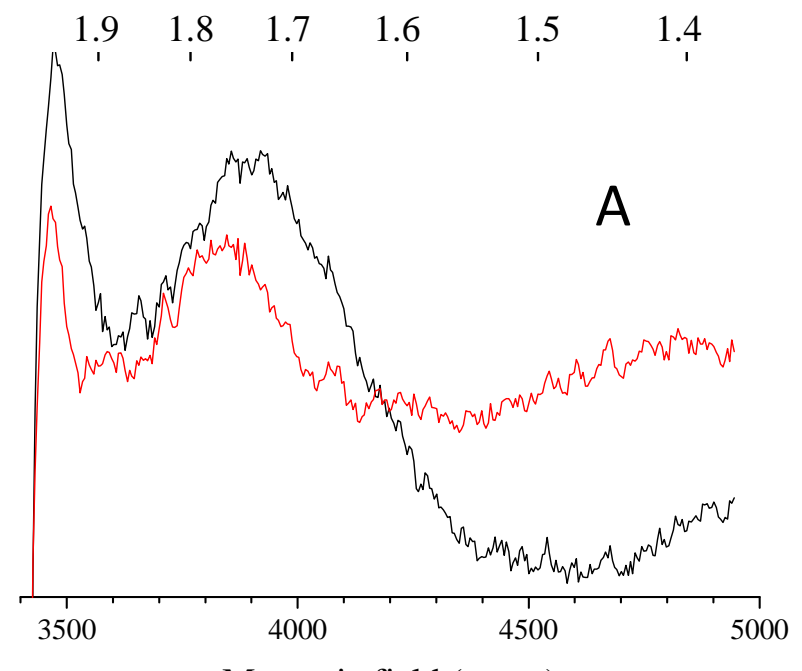

Magnetic field (gauss)

$g$ value

$\begin{array}{cccccc}1.9 & 1.8 & 1.7 & 1.6 & 1.5 & 1.4 \\ 1 & 1 & 1 & 1 & 1 & 1\end{array}$

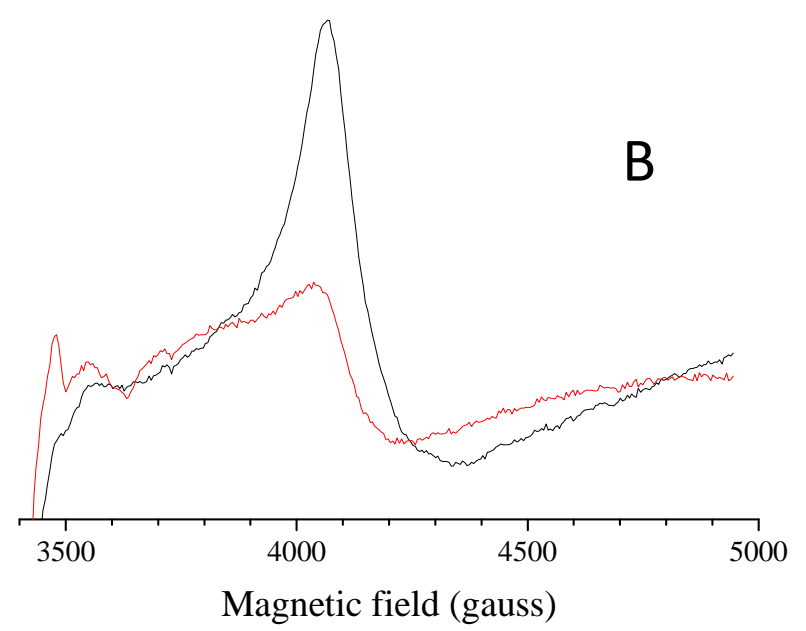

$g$ value

$\begin{array}{cccccc}1.9 & 1.8 & 1.7 & 1.6 & 1.5 & 1.4\end{array}$

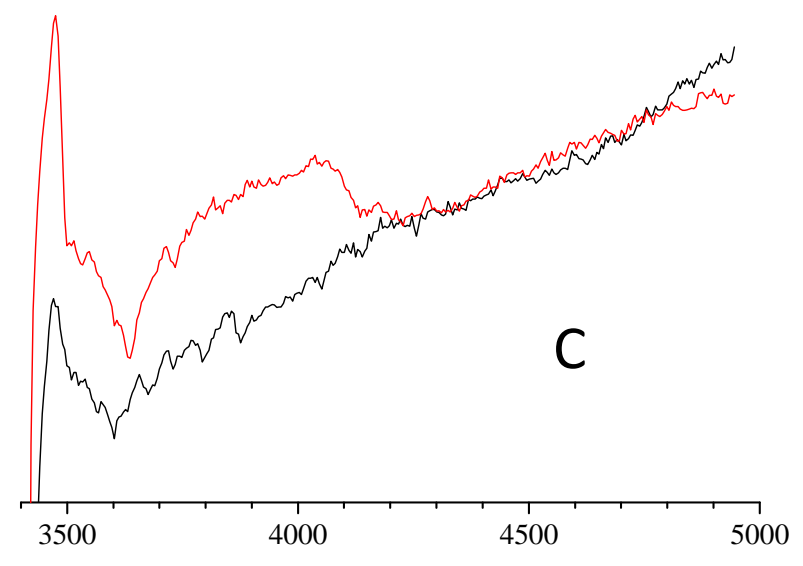

Magnetic field (gauss)

$g$ value

$\begin{array}{cccccc}1.9 & 1.8 & 1.7 & 1.6 & 1.5 & 1.4 \\ 1 & 1 & 1 & 1 & 1 & 1\end{array}$

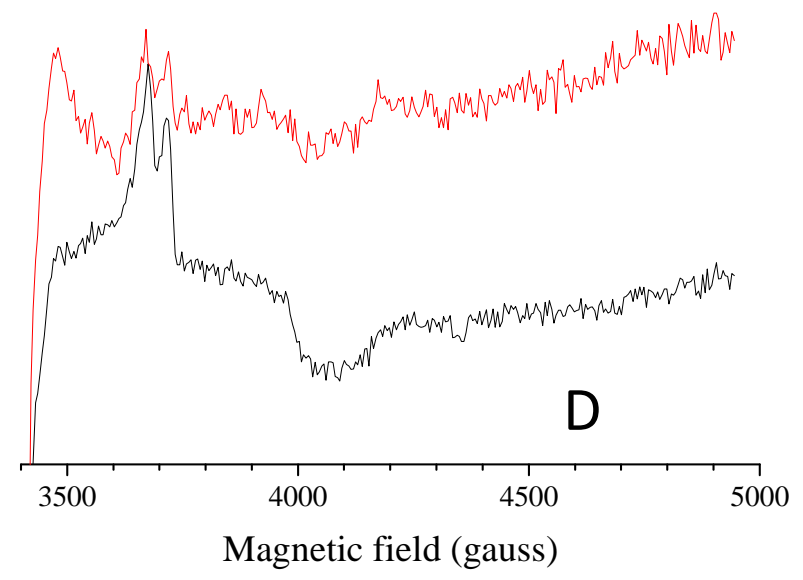

